\author{
Mario Antonio Solano Ramírez \\ Salvador Héctor Soriano Rodríguez
}

\title{
La justicia en la Constitución
}

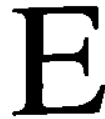

n el presente trabajo se pretende colocar de relieve si en realidad la justicia es un fenómeno estático e inmutable en la perspectivas de los ordenamientos positivos, en especial el nuestro y se intenta a su vez presentar la forma en que la justicia informa el ordenamiento jurídico para la consecución de los diversos valores de la normativa constitucional.

Por otra parte, nos proponemos realizar una valoración conceptual de la justicia, a través de la cual tendremos un punto de expresión que nos permita mostrar la incidencia de la justicia en nuestra propia realidad y su realización en el ámbito que nos es propio. Esta valoración conceptual de la justicia nos permitirá detallar los objetivos que tal valor persigue en el área constitucional.

Se pretende, a su vez, retomar la justicia dentro de canones que nos sitúan en una etapa anterior y que luego transitan a los Estados Modernos y de éstos a la actualidad. Ya es sabido que el concepto de justicia viene esgrimiéndose desde tiempos antiguos, desde las grandes civilizaciones, y entre ellas hay que acatar la referencia ineludible al ámbito griego. Recuérdese de como los más grandes hitos en la teoría de la justicia, incluso para nuestra era vienen siendo la expresión de Platón y Aristóteles, quienes reflexionaron para conceptuar una noción de justicia que se acercara a las relaciones humanas bajo el parámetro de lo armonioso. Grandiosas ideas que aún perduran y que serán reelaboradas por los filósofos de Edad Media, Moderna y Contemporánea.

Siguiendo el esbozo anterior, hemos dividido la exposición en cinco partes lundamentales: la primera, nos mostrará de como la idea de justicia se ha suscrito en la historia; la segunda, la idea de Constitución y el rol que suele jugar con el reconocimiento de la justicia en su seno; la tercera, considera ya un valoración conceptual del fenómeno justicia visto en esencia a partir de su concreción valorativa en la norma fundamental; la cuarta, intentará explicar hasta dónde la justicia como valor puede ser considerada obligatoria en la actuación judicial; y la quinta, prevee un breve recorrido argumental acerca de la relatividad o absolutez de la justicia. Por último mostramos al lector las conclusiones del análisis de 
esla exposición referida a "la justicia en la Constitución".

\section{La idea de justicia}

Como hemos manifestado en nuestro preámbulo, la justicia viene discutiéndose desde tiempos antiguos. No es un invento del presente, ni mucho menos una creación aislada en un territorio determinado. Es todo lo contrario. La justicia viene asimilándose en el pensamiento, especialmente en el filosófico, desde mucho antes que llegara a exponerse por el constitucionalismo modemo y contemporáneo. Claro está que la afirmación de la justicia en el tiempo expresa ya de si cierta constancia, dirfamos que cierta permanencia; al menos como «término" y ése es el primer supuesto que debemos atender. Se habla de "justicia" en la Edad Antigua como en la Edad Media y nuestros oídos son afectados nuevamente en la actualidad con la preponderancia de la palabra. Insistentemente la locución tiene una existencia estable cuasi absoluta (especialmente dentro de los que la aceptan como concepto viablel) que nos ubica prácticamente dentro de un ambiente formalista; formalismo que se expresa en el derecho natural y más tarde en el derecho positivo.

El formalismo tal y como lo concebimos en estas líneas se delata en los intentos de conceptualizar la justicia; con ello se aspira a decimos el «qué es», y es aquí donde se va ir mostrando la primera dificultad y la más importante. Porque a través del formalismo llegamos a decir casi al unísono por la mayoría de autores que la justicia es armonía, que la justicia es lo fundamental, que la justicia es el principio que sirve para ensamblar el resto de fines y valores en las relaciones humanas y en las instituciones creación del ente estatal2; pero el desacuerdo se nos presenta cuando hemos de hacerla realidad, cuando hemos de practicarla.

El problema está en que la justicia se concibe normalmente en el arquetipo de las formas; se dice que es dar a cada quien lo suyo; pero ¿qué es lo que debemos entender como lo suyo? Dejamos abierta la interrogante por el momento para pasar a ver la justicia en el contexto histórico, de cómo esa justicia va variando en el tiempo y suponiendo nuevos soportes en la vivencia del hombre, especialmente en lo que respecta a los criterios para mostrar la armonía y los criterios para lograr la consonancia de los fines y otros valores que agrupa. Una vez visto esto nos detendremos en la concepción de Constitución y la importancia que posee para con la justicia; luego pasaremos a realizar una valoración conceptual de forma y contenido de la justicia en la Constitución. Tópico en el cual nos enfrentamos a la dificultad más importante y con el cual lo polémico arde frecuentemente. Es allí donde la radicalidad de los criterios para optar deben de expresarse, para evitar contenidos que se igualen a lo formal y para eludir contenidos que brinden el espejismo del emotivismo en su conceptualización.

La Teoría de la justicia cabe en la historia y es necesario observar su evolu- 
ción por la transformación que ha tenido. Eso nos servirá para observar qué puntos pueden ser los consecuentes para retomarla en nuestra Constitución, y para mostrar de nuevo si la justicia es simplemente una justicia constitucional, si es supraconstitucional, y si esa justicia en la Constitución se convierte en la justicia justa o de otro modo en una justicia "injusta".

En este debate histórico de la justicia arriba mencionado, vienen movilizándose las diversas concepciones. Nosotros vemos plasmadas en ellas diversos elementos que ya se han venido planteando de manera sistemática por diversos autores.

Recordemos el revuelo que resurge en la Edad Media, y que no es sino un encuentro al planteamiento tradicional de la Grecia Antigua caracterizada por la razón y que la grandiosa época Romana lo torna hacia el derecho; la moderna la sigue asumiendo predominantemente desde el derecho, pero con rasgos absolutos en el surgimiento de los Estados; luego, al comienzo de la nueva era, con unos modelos selectivamente liberales inmersos en el Estado de Derecho y en el que se encuentra consolidado el modo de vivir a través del capital, y que ante las desgracias que ocasionará en un tiempo posterior verá reflejada los intentos de corrección moderada por medio del surgimiento de los derechos económicos, sociales y culturales reconocidos en el Estado Social de Derecho; en la contrapartida del sistema a su vez otros intentarán popularizar un tipo de igualitarismo total, en detrimento de la libertad por medio del socialismo radical, y la utopla comunista; más tarde, los contemporáneos, querrán hacer un prototipo más acabado por medio del Estado Democrático, pretendiendo ensamblar la libertad e igualdad; y que en los diversos sistemas cobran un nuevo auge en la modernización de los Estados bajo pautas que en el hoy parecen representar la prevalencia de un liberalismo modificado que prioriza al individuo social en sus derechos individuales, más que en sus derechos sociales, económicos y culturales.

En este recorrido se viene plasmando de esta manera la justicia desde planos intuitivos y, supuestamente evidentes; proponiéndose desde un derecho natural en la que la razón universal expresa la inmutabilidad de la justicia adhiriéndose a la divinidad, aprehendiéndose de lo teológico, y apuntando hacia lo teleologico como el camino de las consecuencias y metas a lograr; o bien concentrando otros su teorfa desde el reduccionismo positivista; o a veces tratando de atenuarlo desde la observación de un realismo no sólo jurídico, sino predominantemente social e histórico ${ }^{3}$. Indudablemente este es un intento de sistematizar la teoría de la justicia - la cual no pretendemos dejar de lado-.

Consecuente con lo anterior, los primeros aspectos relevantes están en las visiones griegas que venían incluidos en el pensamiento filosófico de los mismos; así, la justicia presentada está en la amnonía que se representa en el cosmos, en las divinidades, en las virtudes, en la aritmética, en la religión y a lo cual como se ha dicho continuará más tarde en el nuevo ente que surge en la modernidad: El Estado. 
A continuación mostraremos el avance histórico de la justicia, desde las primeras visiones. Apuntamos que en un primer momento lo haremos desde el punlo central que ha significado para la filosofía griega. En este contexto nos situamos con la vertiente y el eje principal que para efectos explicativos nos sirve de mayor plenitud. Partimos del centro socrático en la explicación. Y ello es así, en tanto Sócrates ha sido visto como el punto bastión a partir del cual es posible dividir la filosofía griega. El antes y el después. De esta manera, los presocráticos, los sofistas como escuela contrapuesta al centro socrático, y las diversas manifestaciones posteriores a la época de la filosofía socrática con sus exteriorizaciones en las escuelas mayores y menores son un buen presupuesto didáctico para no entrar en una serie de confusiones.

\subsection{La justicia de los griegos.El período presocrático. La predominancia de las ideas cosmogónicas. Y las primeras ideas de la justicia.}

\section{I.I.I.La justicia Cósmica.}

La Justicia desde los primeros tiempos de la tradición occidental fue una preocupación fundamental con gran importancia como lo puede tener en los tiempos actuales. Los filósofos dentro de la escasez de recursos tecnológicos con que contaban, por no decir ninguno, comienzan a razonar y a preguntarse en torno a su realidad. Sus investigaciones les llevan así, en una inicial instancia, a ver en el universo una preliminar apelación.

En esta concepción, el universo es el centro de atención. Es la acentuación de su importancia en las primerizas aseveraciones e incursiones de los griegos, en vista a explicar su realidad. El cosmos, las estrellas, los seres que habitan el más allá de la tierra, protagonizan las iniciales elucubraciones que han de manifestarse de la justicia. En el universo se refleja una especie de orden y estabilidad inmanente, y desde el cual sc irradia el devenir de la existencia humana. Es el universo el parámetro que puntualiza la partida; generando o disolviendo, inmovilizando o dinamizando las conductas, proponiendo y contraponiéndolas. Entre los representantes de esta corriente que esquemáticamente presentamos hemos de ver:

Primeramente al filosófo Anaximandro de Mileto (610-546 a de J), para quien la justicia (diké) está en el universo (kosmos). Este autor nos remite a una similitud con la organización política de su tiempo en la que la senda se recorre por una ordenación originada en el kosmos. Es algo así como una polis grande la cual está sometida a una ley ordenadora. Así la justicia es la presidencia de "la generación y disolución de los seres particulares"4.

Otro protagonista de la corriente cósmica hemos de encontrarlo en Parménides de Elea ( 475 a de J), quien desde su filosofía muestra una retribución total no sólo de los hombres, sino en los astros;a tal punto que su concepción retoca una 
justicia vengadora (Themis y Diké) que separa la noche del día, la verdad de la opinión. Es a su vez, un principio inmóvil, uno y eterno que asegura la permanencia del ser. Esto le lleva a explicar que los cambios que suceden en los seres son tan sólo apariencias. Es decir, son las exterioridades de las cosas que se llegan a conocer por medio de los sentidos, los cuales representan un conocimicnto de primer grado y superficial que se denomina opinión (doxa). Para llegar al verdadero ser habrá de utilizarse la razón, y así alcanzaremos las verdades y el conocimiento universal y eterno. 5

La justicia convertida en lucha y planteada en una realidad que se transforma constantemente y eternamente, es el papel que demuestra Heráclito de Efeso (535-470 a de J.C.), para quien la lucha es el motor del cambio ante el choque que se da entre los contrarios. Según el Profesor V.S.Pokrovski, en Héraclito se refleja que todo se efectúa por un "intercambio contrapuesto"; siguiendo ésta lógica, la armonía emana del choque entre los principios opuestos y su lucha.6

Heráclito acentúa su explicación en que cada cosa es distinta de las otras, además de ser en forma constante diferente a si misma. En esta lónica, la esencia de las cosas no es el ser, sino su devenir. Lo cual nos presenta por tanto, la existencia de un perpetuo cambio que nace de la oposición de las cosas, de la lucha y la necesidad. El perpetuo devenir está regido por el logos que permite la fusión armónica de los opuestos, es decir se tolera que los opuestos se unan en una síntesis superior. El logos se expresa en el fuego "el cual se nutre de la destrucción y engendra y consume las medidas en ciclos cósmicos, separados por conflagraciones universales que son como los juicios finales de cada uno de ellos. El logos mantiene en su órbita a los cuerpos celestes"7

En la versión de Fernández Galiano se recalcará la predominancia de la visión cosmológica, colocando la justicia en presencia de la diosa Diké, la que resulta fundamental para dotar de armonía al universo que trata de explicar. La labor de Diké radica en la vigilancia de los movimientos del universo para lograr el orden en el cosmos. Fernández Galiano recuerda en forma similar a Truyol que Heráclito afirmaba que las furias y los Ministros de la justicia harían volver al sol a su órbita, si este se excediera en sus medidas. La visión cosmológica de Heráclito es confirmada además, por la enunciación del deber ser de las leyes humanas - nomos- en el sentido que éstas deben atender a la ley única divina. En esta forma, las leyes de los hombres deben reflejar la justicia que late en el cosmos.8

\subsubsection{La Justicia aritmética y geométrica.}

Uno de los temas frecuentemente analizados en lo que respecta a la justicia, es la concepción matemática de la misma, pensamiento que es posible seguirlo inscribiendo en el contexto del período cosmológico griego. La variante en este punto es la preocupación por hacer de la justicia, bien un número, o bien una 
figura geométrica. Es así como se va ir presentado en algunos autores en especial entre los Pitagóricos (Pitágoras de Samos, segunda mitad del siglo VI).

En el mismo orden se argumenta, que con los pitag6ricos nos encontramos con la repetición del término y del formalismo. De esta forma retomando el esbozo aritmético precedente, la justicia se entiende como: a) medida determinable en forma maternática que expresa una relación de igualdad; b) se funda en el orden natural, presidida por la ley del número, representada en un número cuadrado producto de dos factores iguales; c) La imagen de la justicia es el cuadrado geométrico, porque tiene cuatro lados iguales; d) El número ejemplo de armonía es el cuatro, ya que sumándolo o multiplicándolo es el único número que se forma con las mismas cifras9.

La preocupación por explicar la justicia en el ámbito geométrico seguirá con "Amblijos", para quien la justicia sigue siendo en esencia una figura geométrica, pero ya no un cuadrado, sino, un triángulo rectángulo escaleno producto de la relación entre el cuadrado de la hipotenusa y la suma del cuadrado de los catetos. Es con esta fórmula que se introduce la igualdad, la finitud y la mesurabilidad.

\section{J.J.3. La Justicia en la literatura}

La justicia fue una preocupación constante en el ambiente griego, que obsesionó en no pocas ocasiones a los filósofos como intelectuales específicos del campo. Sin embargo, el terna de la justicia vuelve a concernir a otras esferas griegas, que sin renunciar a la filosofía, quisieron incursionar en la materia definitoria de la justicia desde sus cscritos como literatos.

En Homero se habla aisladamente de justicia, y coloca la le de la justicia en Zeus, quien actúa caprichosamente y en algunas otras arbitrariamente. Themis (la esposa de Zeus) aún no es una ordenación de conjunto armonioso, y adquiere un signo autoritario por su vinculación al rey, delegado de Zcus.

En Hesíodo, se recoge el tipo absoluto del ordenamiento moral. Y escribe conceptualizadoramente en su teogononía a Themis (orden) como esposa de Zeus, sus hijos Eunomonía ( la seguridad-o recla legalidad), Diké (la justicia) e Irene (la Paz). La justicia es ya, a diferencia de Homero, un signo regulador de la igualdad en la reciprocidad. Al escribir Hesíodo otra de sus obras titulada «los trabajos y los días" deja entrever la edad de la decadencia en la polis, donde los jueces son devoradores de prebendas, y en donde los malos engañan a los buenos. En este contexto Diké funciona denunciando así las injurias que se dan los hombres, lo cual lleva a su padre Zeus a aplicar el castigo en forma de desastres por las injusticias cometidas individualmente o colectivamente. Hesíodo deja mucha concreción en la atracción del mal divino por parte de las sentencias injustas; quizá, como dirá Prieto, por la propia experiencia del autor, al pelear una supuesta herencia con su hermano y al no conseguir que los jueces dieran una sentencia justa10. 
Cuando se aborda otro de los famosos literatos como es Esquile (525 -456) encontramos que la justicia se denota bajo la presencia de la ley cósmica del talión en el que todo desafuero exige la retribución. La justicia sigue teniendo un origen divino, y continua siendo medida y equilibrio. Zeus es el garante de la no impunidad y el equilibrio en el delito, y la sanción es atribución de la polis.

El supuesto universal basado en el soporte de las divinidades griegas sigue teniendo una manifestación en S6focles (497-406), quien detallará la imposibilidad de contradecir las leyes divinas, y la consecuencia de la invalidez de las leyes de los mortales al entrar en oposición con las leyes de los dioses.

Cuando se trata de fundamentar con hechos la experiencia de la influencia de la justicia divina en el campo terrenal griego, sale a relucir Herodoto de Halicarnaso (484-425), quien recoge la historia como graduación de la justicia. En la historia está el fundamento que no olvida la justicia divina. Así, la historia es el juicio divino. Y la justicia actúa en la vida de los pueblos por mandato de los dioses. Véase en esta forma el triunfo de los griegos sobre el imperio persa.

\subsection{Los sofistas.}

\subsubsection{La justicia antropológica.}

El hito primogénito en la distinción de lo divino y las leyes terrenales, originariamente puede encontrarse en la sofística. Corriente en que la crítica hacia el ordenamiento natural se refleja al hacerse la distinción entre la phisis y el nomos, entre la ley natural y la convención. Desde ahí, los sofistas vienen a conformar una corriente filosofica muy especial en la historia de los griegos. Aunque, cuando se llega al punto de la justicia, los solistas, dirjamos, no se alinearon en un bloque uniforme, más bien se esparcieron en categorías que iban de lo radical a lo moderado.

Así, el radicalismo sofista de Trasímace construye la justicia dentro del marco de lo que es conveniente para los gobernantes. Lo justo se expresa en la ventaja que reporta para el más fuerte. De esta manera, las bases de la justicia en la sociedad se encuentran en el interés y en la conveniencia. En este sentido el gobierno se vale del nomos para favorecerse, legitimando sus mandatos y haciendo creer a los gobernados que eso es lo justo.

Con Caliclés otro radical sofista, el derecho positivo es algo así como una barrera del derecho natural que se construye artificialmente, violentando el desplicgue de las individualidades superiores, poniéndolas en consecuencia bajo el común denominador de las multitudes. Evoca, en la percepción de Fernando Prieto, al superhombre de Nietzche, al medir la variabilidad de la justicia, y de lo que conocemos como injusticia. De aquí, la justicia se plasma en toda acción que se quicre situar por encima de la multitud, opinión que a su modo de ver es una 
respuesta al orden natural, mucho menos lo serán las leyes que aparte de ser un invento de los mediocres, sólo buscan la protección de los más débiles. "Si hubiera un hombre con suficiente fuerza... pisotearía todas nuestras fómulas, conjuros y encantamientos y todas nuestras leyes que son contrarias a la naturaleza".11

Desde la moderación sofista aparece Protágoras de Abderas (480-410) quien se aleja del individualismo anterior y fundamenta la armonía social en las virtudes del pudor y la justicia que poseen todos los hombres (quienes no las posean la sociedad debe deshacerse de ellos). Por lo que todos están llamados a participar de las funciones públicas. Lo justo es determinable en el campo de la utilidad social. Y la pauta de lo justo está en el nomos, que debe no dejarse retener por la phisis. Es interesante que Protagoras da rienda suelta a un cambio de concepción acerca de lo justo. Contemporáneamente, dirfamos, que está dentro de una senda, más que de absolutización de la justicia, hacia su relativización. La perspectiva que nos permite admitir esta opción es que, en Protágoras, encontramos suficientemente autorizada la asunción de la convención. La justicia no es por tanto igual en todas partes, ya que no es universal y eterna, sino, relativa. Relatividad que va colocar en lo concemiente a la convención la noción de lo Justo. En las palabras de Prieto "la mentalidad tradicional afirmaba que lo justo era igual en todas partes y siempre y que la ley, en la medida que fuera justa, tendría que ser universal y etema. Protágoras le da vuelta al argumento y afirma que la ley es justa por acuerdo de la comunidad, y por lo tanto no puede ser universal y eterna" 12 .

Con toda esta división contextual que tocó las humanidades intelectuales de los sofistas, es innegable que al mismo tiempo causaron estupor con otras nociones, entre las que el historiador de las ideas políticas resalta siempre el ataque ferviente que ocasionaron contra las ideas aristocráticas; con lo cual hacen suponer la conmoción que pudieron ocasionar en una sociedad asentada sobre tales ideas; principalmente cuando se aproximaron con sus prácticas a unas enseñanzas abiertas a todos, combatiendo la mentalidad elitista de la época, y aproximando a los atenienses a la idea de democracia; habituando al alumno al pro y al contra de cada tesis, y enseñándole el tema de la oraloria. Platón verá despectivamente en está última el arte de manipular, de asustar y manipular al pueblo tal como el domador lo hace con su fiera.

\subsection{La contrapartida de la sofistica: Sócrates.}

Si la idea de la sofistica se dirigía en contra de los planes aristocráticos, el socratismo se dirigirá a defenderlo y a negar los beneficios de asentar la Polis en un sistema democrático. Sin embargo, si bien es cierto que el programa socrático era dirigido en especial forma contra los sofistas, había en su discurso un embate contra la moral colectiva tradicional, al predicar una moral basada en la conciencia individual crítica. En este sentido es que aparece S6crates (469-399), quien 
coloca la justicia como la condición de la felicidad. Y en esa división del orden divino y el terrenal, retoma una confianza en la justicia divina separada de la justicia de la polis. Así propone una razón no contestaria de la justicia ciudadana cuando se muestra ésta como injusticia. Su regla y su ejemplo al beber la cicuta puede llevarnos a la interpretación de no pagar la injusticia con injusticia ya que no es mejor, ni más beneficioso, cometerla. Es más, habría que sufrirla, y expiarla con el cumplimiento de la sanción siempre y cuando no hubiese ouros afectados con tal cumplimiento. Con dicha conducta ha sido visto, según Truyol, que el amparo de la desobedencia ideológicamente incluida en la juslicia terrena no debe llegar a los extremos de poner en peligro las instituciones sociales, especialmente si la ciudad se halla cimentada en una realidad ética y en el orden divino (Truyol).

En toda esta explicación socrática pueden sacarse a tras luz tres posiciones desde lo jurídico: la primera, aparentemente presentaría una forma de positivismo legal, lo cual, en la interpretación de Prieto no puede asumirse; el razonamiento que utiliza es que hay una obligación de someterse a la polis, siempre y cuando la sumisión haya sido libremente elegida; además, con tal sometimiento no existe una reducción de aceptación del positivismo de la polis sino, simplemente, la afirmación de la injusticia, y la existencia de un criterio superior de justicia. En segundo lugar, la sumisión no es incondicional, ya que se condiciona la injusticia cuando ésta no afecta a terceros; Prieto recuerda que Sócrates resistió a los treinta Tiranos. No obstante las dos interpretaciones anteriores podría añadirse una más; al proyectarse el honor como cuestión de la primera generación de los valores de la tradición occidental asumidos en la polis griega, más la valentía y sacrificio personal13, con lo cual, retomando la filosoffa esenia explicada por Wilson se logrará considerar que la muerte si llega con honor es mejor que la inmortalidad 14.

\subsection{El tiempo posterior a Sócrates: Platón y Aristóteles.}

Existen prácticamente en nuestra era dos filósofos que han marcado profundamente sus huellas en cualquier tcoría que quiera hacerse de la justicia. Uno de ellos es Platón, el otro Aristóteles.

\section{I.4. I. La Justicia como Virıud.}

Platón (427-347 a.d.C.) es aparte de un filósofo clásico, un individuo que ha impactado a la humanidad entera con su idealismo que deviene de las influencias de su maestro Sócrates 15 . Desde ésta circunstancia la justicia en Platón retienc un punto de vista que lleva a una jerarquización de clases; creando de este modo para el ciudadano una dependencia de la sabiduría del rey filosofo; clase que quizá no sea la peor, pero tampoco la más apropiada en el jucgo de sus soluciones. Sitúa así una dependencia que coloca por arriba a los enuditos y por abajo a los ignorantes en el manejo de las cosas públicas, pero dicstros los 
últimos, en proveer los elementos útiles para la sobrevivencia. El planteamiento tiene consonancia con su estado ideal de carácter aristocrático que vendrá a ser presentando en su "República". Es así que en ese estado la justicia se realiza, dando a cada quien lo que le corresponde.

Haciendo modelos micros y macros, la justicia de Platón es plantada en el hombre y en el Estado. En el primero, es la virtud cardinal que dota de armonía a las tres virtudes elementales humanas; $y$ en el segundo, es una jerarquización de clases detrás de la cual el sometimiento al filósofo gobernante y a los guerreros de parte de la clase que se dedica a la salisfacción de las necesidades básicas puede denotarse con mayor claridad.

Cabe añadir que el afán de Platón acerca de su tentativa formuladora de lo justo tiene que ver con su intencionalidad de modificar la estructura de la polis de su tiempo. Podemos descubrir como ansía transformar la estructura social de Atenas, al empeñarse con las proposiciones en su esquema de justicia. Se observa ello en la insistencia de las tres clases, tratando de dar una nueva forma a la organización social-política de su tiempo, estigmatizada también en tres categorías; y en cuanto que en Alenas existian igual número de estamentos, básicamente hablando: "los esclavos" en el sentido propio de la palabra, marginados de todo tipo de derechos civiles y políticos, y acerca de los cuales se presentaban ya scrias dudas sobre la humanidad en tanto ser hombre, o situarlos en un posición intermedia de animales o seres humanos 16; "los metecos", extranjeros de ouras ciudades estados o del exterior, que según las denominaciones de Salom 17 , eran hombres libres pero no ciudadanos; 18 y "los ciudadanos", que dirigían y disfrutaban de la ciudad- estado, y más que en virtud de los derechos, libertades - posibilidades de las que pudieran beneficiarse, podían definirse en razón de que el ciudadano podía disfrutar del carácter colectivo de su ciudad 19. Platón está en éste afán transformador y hasta cierto punto revolucionario, e intentará así, la introducción de su ideal por medio de la macroestructura política, la cual se vuelca en una trilogía ascendente y jerárquica de: gobernantes, guerreros y comerciantes-artesanos-labradores. Proposición que a pesar de perseguir un cambio en la división estamental, sigue conservando el tipo esclavista de la realidad griega.

La justicia simboliza uno de los puntos fundamentales en la teoría platónica desde sus escritos en la "República", y como ya los planteamos en un inicio se esboza desde el hombre y desde el Estado. Desde el hombre Platón construye su tcoría en vistas de que encuentra en éste tres virtudes cardinales: la prudencia, la fortaleza y la templanza y una cuarta de carácter superior que es la justicia. La primera rige la actividad racional del hombre, en su labor del conocimiento intelectual de la ideas; la segunda, que rige la acividad irascible del ser humano, la cual tiende al mundo de los impulsos; y la tercera que consigue la sumisión de la actividad concupiscuble del hombre,- - la actividad concupiscible está relaciona- 
da con las actividades vitales, que al traducirlas no son más que una correspondencia con las funciones en puridad biológicas-. Y por último, la justicia será quien proporcionará el equilibrio, colocando en su labor de hacer, la armonía en el actuar de las ures virtudes sin que ninguna o alguna pueda imponerse a las demás.

El micromodelo de la justicia se expresa en unas especiales nociones de virtudes que posee el hombre, a la vez el macromodelo de justicia platónico se expresa en una clasificación que distingue diferentes clases de hombres. La primera, la de los gobernantes, defínida como una raza de oro, siendo su virtud la prudencia y la vida racional. La segunda, raza de plata, integrada por los que se dedican a la defensa, en donde los guerreros, son los que tendrían la misión de defender a la ciudad; la vida irascible y la virtud de la fortaleza son incluídas como fuentes principales de su ámbito. La tercera es la que corresponde a la raza de bronce y de hierro, constituida por los artesanos, labradores y comerciantes; y en general, por los que están dedicados a la satisfacción de la necesidades básicas de la polis. Los sujetos incluidos en esta tercera clase están sumisos a la virtud de la obediencia y templanza. En la perspectiva presentada, los estamentos más importantes son los dos primeros, a quienes se aplica la norma de abolición de la familia y la propiedad privada, para protegerles de la irresponsabilidad en el ejercicio de sus funciones; norma que no será aplicable al tercer estamento. La justicia en el macromodelo conserva la visión original del micromodelo, en el sentido de proporcionar armonía a la polis, bajo la forma de que cada uno, cada miembro y cada estamento deba desempeñar la misión propia, si es que quieren conservar el equilibrio social.

Al final de cuentas, la justicia en Plalón es un principio de armonía y cumple la función de determinar el campo de acción de las demás virtudes. Es la virtud universal que se aplica a el hombre. En consecuencia, las virtudes que concurren en él deben estar coordinadas por esa virtud universal; con ello el intelecto debe regirse por la prudencia o la sabidurfa, la voluntad por la fortaleza o el valor, y los apetitos por la templanza. Asimismo en referencia a esa justicia que tutela la armonía entre las diversas partes, cada uno debe hacer lo que le corresponde. En la ciudad-estado griega el principio se recaba bajo la distribución de funciones. Por lo que será justo si los gobernantes son sabios, si los guerreros defienden y si los artesanos laboran. En definitiva, es una interpretación política de la justicia que se caracteriza por la poca movilidad intersocial, algo así como estar tranquilo con el rol que a cada quien le toca hacer.

Cuando Aristóteles asume el rol de la juslicia, será más concreto, y si podemos verle de otro modo, intentará acusar una mayor practicidad a la hora de decir el "qué es" y de mencionar "cómo se ocupa». En eslas circunstancias verá que es la virtud total, siendo la medida de proporcionalidad de los actos; en otras palabras, el medio equidistante entre el exceso y el defecto. Coloca en consecuencia dos especies de justicia20 que en definitiva intentan combinar el princi- 
pio aristocrático y el principio popular. Así tenemos por un lado: a) La distributiva: al definirla desde esta perspectiva la presenta como una relación de proporción entre fama, propiedad, y valfa de la persona para los conciudadanos. Aquí resulta entonces una noción de justicia como dar a cada quien los honores y bienes en la comunidad según sus méritos; deduciéndose que al dar igualdad de trato en méritos desiguales estaríamos violando el principio. De donde habría que aceptarse que lo que se tutela a través de esta forma no es otra cosa que el énfasis de las relaciones personales basada en el respeto por el principio de la desigualdad de Iratamiento o la defensa de un principio aristocrático. B) La correctiva o sinalagmática, que incluye la conmutativa y la judicial. El cambio es el interés que se coloca en las cosas populares, a diferencia de la anterior, en la cual, el interés se coloca en la diferenciación con escala geométrica de las personas. El giro de la correctiva, según Pokrovski es el asentamiento en las transacciones jurídico civiles, a las que se le agrega la acción reparadora de los jueces; de ahf su preferencia de llamarla justicia "niveladora", en cuanto la pretensión de nivelares lo que constituye objeto de intercambio. Mientras que la distributiva se fija más en el terreno político; de ahí, la distribución de los honores y distinciones según los méritos21. En concreto, la primera de la segunda forma de justicia o sea la Conmutativa se da, cuando incurte en ella la voluntad de los interesados, con lo cual presenciamos el ámbito de las relaciones voluntarias o de cambio; en las que se confiere una especie de igualdad entre lo que se da y lo que se recibe. Y la justicia judicial cuando se impone el castigo por intermediación del juez en contra de la voluntad de los interesados. Mostrándose así, que se intenta una paridad entre el daño y la reparación, entre el delito y la pena gracias al operador jurídico que decide.

\subsection{La justicia en los filósofos menores: Epicúreos, Estoicos, Cínicos.}

\section{I.5.I. La justicia en los Cínicos}

Uno de los signos predecesores a los estoicos que se adelantan casi un siglo a la crisis de la Polis se expresó a través de la protesta de los cínicos. Ciudadanos o extranjeros de menor categoría que podían catalogarse como los marginados "políticos". Antistenes (445-365) y Diógenes (-324) son los símbolos de la sabiduría cínica en cuya afirmación básica está la autarquía de los hombres; se valúa que lo único necesario para vivị es lo que está dentro de sus facultades. Los cínicos recurrieron al desprecio por la familia y la propiedad, la ciudadanía y el prestigio social; en general su desdén se mostró en contra de todas las convenciones institucionalizadas de la época y en uno de sus puntos muy concretos en contra de las normas de convivencia, aunaban sus esfuerzos para que cada ciudadano se dictase según su propia sabiduría dichas normas 22

Desde las tesis expuestas, la justicia de los cínicos pueden presentarse desde un alto nivel individual, con un espacio muy reducido de acción. Individual en 
tanto han venido pregonando por la autarquía de los hombres. Con esto, la justicia prácticamente se vuelve realizable para un pequeño grupo de hombres y se restaura en este contexto como un ser irrealizable en situaciones mayores. Interpretación que no debe ir en menosprecio de ciertos postulados que llevaron a los cínicos al igual que a los sofistas por el pregón de la igualdad para los hombres; con lo cual se vuelve ya en sí un punto salvable para plasmar una idea de justicia. Recordemos su tendencia universalista al querer demostrar que los ciudadanos no lo son de una polis, sino de todo el mundo.

\subsubsection{La justicia en los epicúreos.}

Con los epicúreos la idea de justicia toma una camino diferente. Epicuro (337 a. de. C.) es su máximo representante, para quien las inquietudes primordiales están por las sendas del materialismo, hedonismo y utilitarismo: A) Materialismo, debido al combate que se realiza contra el hombre religioso, como hombre colectivo y la transformación que predica en la realización de un hombre autónomo. Es una opción materialista para que el hombre se desligue de la carga que soporta por las religiones, ya que éstas le someten al miedo y a temores infundados. No obstante, su tesis no es un negación de los dioses, simplemente es una muestra de la despreocupación de los dioses por las cosas humanas. La decadencia de la Polis es un ejemplo palpable de la situación que confirma su argumento. Así, el destino de los hombres no está delineado por los dioses ni por la religión, el destino de los hombres está únicamente forzado por el hombre en el camino a lograr su propia felicidad. B) Hedonismo, en tanto que la búsqueda de la felicidad se basa primordialmente en el placer. La regla a que debe atender el ser humano para lograr su felicidad es la obtención del máximo placer y evitar el máximo dolor, somático o psicológico; según Epicuro el mayúsculo placer está en la amistad. C) Por último el Utilitarismo no viene a ser más que la expresión del principio básico social de convivencia. Partiendo del hombre como ser egoísta, esboza la necesidad de una técnica social plasmada en el poder político que dote de seguridad a los ciudadanos y frene el egorsmo innato del hombre. En este aspecto la justicia aparece como cuestión de utilidad y la injusticia como cuestión de perjuicio. A su vez en el contexto utilitario Epicuro planteará la no existencia de una justicia objetiva, sino "la justicia como convención de no hacer daño a los demás". Por eso las normas de justicia cambian, por el carácter convencional que poseen. De ahl que cuando la ley ha dejado de ser útil ha perdido toda cualidad de justicia23.

\subsubsection{La Justicia en los Estoicos.}

Los estoicos han sido vistos como el antecedente del concepto de derecho natural que formulará definitivamente Cicerón. En esto hay dos ideas: una es su pregón por la comunidad de iguales; y la segunda, es el tema del imperio de la ley. Con la comunidad de iguales los estoicos admiten la igualdad de todos los hombres, en principio desde lo interior. Con ello dan voltereta al planteamiento 
aristolélico de la desigualdad que puede haber entre los hombres, y de la vía hacia una sociabilidad reducida, según que solo podemos llegar a una comunidad restringida puesto que los hombres no son iguales. Tampoco los estoicos llegan al planteamiento individualista universalista y utilitario de los epicúreos, pero si resaltan la individualidad desde la interioridad de los hombres. Lo cual, según Prieto, se vuelve inoperativa. La igualdad interior en este sentido no tiene porque tener un reflejo en las desigualdades exteriores, menos en las desigualdades sociales, incluso respecto de la esclavitud. El imperio de la ley es otro retoque de la fórmula estoica. He aquí donde comienza a diferenciarse la ley positiva de la ley natural, y a plantear el modo correctivo que tiene la ley natural respecto de la positiva, y el espíritu crítico que puede tener en relación con las decisiones políticas. 24

Con los estoicos en témininos generales se cierra el ciclo de la discusión de la justicia en el mundo político de los Griegos. Ideas que van a seguir cargando los diversos autores en sus pies de páginas hasta nuestros días. Roma no será la excepción. Sin embargo, es de notar que hay un plus de evolución en la asunción del valor. La llegada de los jurisconsultos romanos y la nueva visión en esencia a partir del "ius", más que de la "razón" como fuerza determinante en los griegos, es el agregado que resalta hasta nuestra era. Así, la idea de justicia comienza a justificarse con el derecho, que para unos será el natural mientras que para otros será el positivo. Después de los griegos, la justicia vuelve a recorrer inquietamente los avalares de la historia y de las sociedades, incluyéndose en ésta forma en el pensamiento de otros y diversos autores que han hecho época con sus discursos.

\subsection{La Justicia después de los Griegos: Las ideas de la Edad Antigua roma- na a la Edad Media:}

Es con los griegos en quienes se observa un gran aporte acerca de lo justo; después de ellos tendremos ideas de la justicia que podemos encontrar en forma especial en autores que presentamos a conlinuación y que son sin duda los más relevantes al tocar el tema de lo justo.

\subsection{La justicia natural:}

Marco Tulio Cicerón (106-43 a de J.) tratará de observar lo justo como la actividad de darse lo suyo. Al respecto toma en cuenta el mérito y la dignidad. Y es en la dignidad donde va encontrar la noción de la igualdad en los hombres. Es a partir de la dignidad que los hombres son iguales, ya que todos saben conforme a la razón que es lo justo y lo honesto. La justicia es la que existe por la naturaleza, si se fundamenta en el interés tiene que ser aniquilada. La ley es el espíritu de Dios, su razón soberana, de donde proceden las leyes de los hombres, las cuales carecen de validez si contradicen la recta razón. El vínculo en la sociedad política radica en las nociones de lo que es justo y de la común utili- 
dad. La ordenada convivencia es el fin de la sociedad y el lugar que realiza la justicia.

Entre los juristas romanos encontramos nuevos intentos de acercamiento a la idea de justicia, el más relevante en este campo es sin duda Ulpiano para quien la justicia es la constante y perpetua voluntad de dar a cada cual su derecho. "Esta descripción de justicia contempla un hábito volitivo de determinado contenido y lo califica como digno de alabanza".25 Lo cual hace ver en Ulpiano un visión virtuosa, valorativa y subjetiva de la justicia. Una justicia que es complementada por el derecho natural que a través de su «ius» facilita los criterios de valoración que nutren la "iustitia". Parece ser que en la visión de Ulpiano se desatiende la contraposición entre virtud y valor como conceptuación de la justicia. No obstante, a pesar de no ser contrapuestos ambos conceplos, los dos son diferentes, ya que el primero, es decir el que enfoca la justicia como virtud atiende a los hábitos consecuentes de la voluntad, mientras que el segundo, en tanto enfoque de valor, presenta a la justicia como un acontecimiento objetivo que en las palabras de Goldschmidt significa «adjudicación de potencia e impotencia» (algo objetivo). 26

\subsubsection{La Justicia Cristiana:}

Es otro modo de abordar el tema. Reciclando en esta forma la familiaridad en primer lugar por una monoteísmo supremo y rector. Confiando en la divinidad, todopoderosa y omnipresente que regula, revela y vigila su justeza entre sus creados. Una íntima expresión de la temática puede ser rastreada a traves del evangelio Cristiano en donde, aparte de tener rasgos suprahumanos en la substancia originaria, al hacerse presente entre los hombres hace culto a las manifestaciones de la no retribución, a la capacidad potencial o ejercitable de resistencia al mal. Ello se expresa en las reglas de pagar el mal con el bien, el perdonar siete veces siete, el presentar la otra mejilla al recibir una bofelada.

No podemos negar que la justicia encuentra su punto central en las enseñanzas de Jesucristo, campo en que las intenciones como íntimas motivaciones de los comportamientos son relevantes. La justicia implica el cumplimiento de todos los deberes para con Dios, de amor para el prójimo, de la santidad y de la perfección moral y religiosa. Sin embargo, aparte de las enseñanzas de Jesucristo podemos encontrar una reelaboración de su pensamiento, adicionado con las ideas griegas, en dos exponentes del iusnaturalismo divino o teológico que hacen revivir la justicia cristiana en una etapa posterior.

San Aguslín continúa hasta cierto punto las remembranzas platónicas-estóicas (rayendo la justicia bajo el signo de la equidad, de la igualdad y del dar a cada uno lo suyo. En su "del génesis contra los maniqucos", (L.II C.X.14), expresa la unión que representa la justicia, en la cual, las tres virtudes: "la prudencia, la templanza y la fortaleza se unifican en perfecta armonía". De aquí, en San Agustín 
se potencia la justicia en el compendio de la virtud. No es ocioso señalar que el ingenio platónico no es copiado absolutamente, más bien es parte y no el todo del argumento agustiniano. Con esto queremos dejar sentado que se va a dar un entronque platónico con la filosofla cristiana esbozada por San Agustín. Siguiendo al Profesor Lorca Navarrete, San Agustín "acoge el genio del platonismo sellándolo con nuevos impulsos que hacen de Dios "no solo el centro de su filosofía y el eje polarizador de su pensamiento jurídico y polf́tico, sino también el principio de la verdad y el fundamento último de la justicia y el orden"27. Lo ideal para el derecho es la subordinación del alma a Dios y del cuerpo al alma. $Y$ lo ideal para el derecho es equidad, la equidad es igualdad y la igualdad es la virtud de dar a cada uno lo suyo. San Agustín parte de la idea que la ley injusta no es ley y que el Estado injusto equivale a un delincuente.

Santo Tomás de Aquino (1224/25-1274), recogerá la versión detallada de Aristóteles en lo referente a la justicia y además algunos ecos de las versiones de Cicerón y Ulpiano. La justicia así vista, es un criterio ideal para el derecho, aparte de ser virtud general. Es dar lo suyo, concebido como todo aquello que le está subordinado o atribuido a sus fines. En su Tratado de la Justicia contenido en Summa Theologica (Secunda secundae, Questiones, 57-59), Santo Tomás define lo propio de la justicia en la forma que antecede: "lo propio de la justicia, entre las demás virtudes, es ordenar al hombre en las cosas relativas a otro" $(2-2, q .57, a .1)$, por lo que propone la siguiente definición: "justicia es el hábito según el cual uno, con constante y perpetua voluntad, da a cada cual su derecho" $(2-2, q .58, a .1)$. La función que cumple es el ordenamiento de las relaciones entre los hombres. La justicia apunta en este sentido a una relación de igualación. En la que la igualdad se da con el otro. La justicia desde esta acepción se observa de dos modos, respecto al individuo y en referencia a la comunidad. "Esto es, que en cuanto el que sirve a una comunidad sirve a todos los hombres que en ella contienen $28^{\text {". }}$. Santo Tomás observa asl una justicia general y una individual, pero la primera en cuanto hace referencia al todo y el todo al bien común es la que se debe de perseguir. La justicia por tanto ordena al todo, al ordenar que cada una de sus partes logre la consecución del bien común29.

\subsection{Justicia liberal: el tránsito al liberalismo y al igualitarismo.}

La Edad Media es un entronque esencial con lo moderno, primeramente por el aporte que el ambiente insular y menos en el continental dotará para las diferentes teorlas en la formación del Estado. En el Continente europeo, la Edad Media ha significado casi un rompimiento con la modernidad, en especial por la conformación del nuevo ente que se absolutiza por medio del Estado. Sin entrar en demasiados detalles sobre lo absoluto, es menester no omitir que es con este tipo de Estado que la justicia en el ambiente moderno comienza con un tipo de germinación diferente, especialmente, porque permitió la unificación de lo disperso, y se crea asf el canal necesario, para ir en el transcurso de la historia dando 
cabida a una retransformación estatal que va de la absolutización, a su liberalización, disminuyendo en consecuencia, el Poder único que el monarca detentaba. En estas circunstancias Bodino marca una etapa de transición a la nueva era al diferenciar el Estado del Gobierno30.

Jean Bodine en su libro la república (libro sexto), dispone que la justicia armónica es en realidad la verdadera y a la que hay que atenerse; la cual a su vez comprende a la conmutativa o distributiva que estaba impresa en la etapa aristotélica, pero que no es simplemente una sola, o cada una por separado; o una mezcla de ambas como pudo haberlo visto Aristóteles. La justicia armónica es diferente al planteamiento aristotélico. En este sentido señala que el error de éste radicó en no haber conseguido compaginar el gobierno aristocrático y el popular. Cabe recordar que es en Bodino en donde comienza a diferenciarse entre gobierno y Estado y ante los desdenes cometidos bajo el imperio de lo absoluto es que ideará la combinación ejemplar del Estado y gobierno aristocrático y popular. Con ello los súbditos no recibirán un tratamiento como niños sino como adultos con el reconocimiento de la propiedad de sus bienes y libertad natural.31

\subsubsection{Justicia positiva}

Con Thomas Hobbes la justicia adquiere un matiz crucial y es de aqui que la misma se identificará con el derecho; y ni siquiera con el derecho natural, sino con el positivo. El rasgo de positividad jurídica que se advierte en Hobbes será llevado aún más lejos con la justificación contractual del Estado en el que hemos de ver que si para Bodino el Estado absoluto era injusto para Hobbes será el justo. Las razones han venido siendo conocidas en discusiones magistrales: antes del contrato no puede hablarse de justicia, a la vez en ese Estado no hay tampoco injusticia, puesto que no hay poder civil lo suficientemente fuerte para obligar a los hombres que lo cumplan y, si este poder civil no lo está, no hay ley. Porque la única forma de justicia está en la ley que se regula por el gobierno del monarca que es absoluto. En consecuencia, lo dictado por el soberano es siempre justo; y por tanto, la justicia en Hobbes, interpreta Gracia, es un acto positivo y no un derecho natural, ni siquiera un derecho negativo, y la cual no puede de ninguna manera verse constreñida por una justicia distributiva 0 conmutativa. La justicia es la voluntad del soberano. Y es él quien establece lo justo o lo injusto. "la autoridad no la verdad hace la ley" 32 .

\subsubsection{Justicia liberal, primero, natural y segundo social o legal.}

John Locke ha sido uno de los autores que clásicamente se han presentado a la defensa del derecho natural, y en la diferenciación del estado de naturaleza y sociedad política-civil. Así aparecen los derechos anteriores, la vida, la salud la propiedad y la libertad y el derecho a defenderlos cuando estos se encuentren bajo amenaza. Sobre este particular es que surge el pacto. El único objeto es el de protegerlos; porque, el objetivo del contrato se convierte en la consecución de la justicia social o legal (la cual no ha de confundirse con un justicia distributiva, 
sino más bien en su negación, cuyo ejemplo encontramos en forma palpable al defender la adquisición de la propiedad individual como producto del trabajo) y la prolección de una justicia natural individual que incluye los derechos naturales mencionados. Según Diego Gracia "La función del contrato social y del Estado no es maximalista, sino minimalista. No tiene otro objeto más que el de permitir el ejercicio de los derechos naturales a la vida, salud, a la libertad y a la propiedad. Cuando el Estado no hace esto, o lo hace mal, es decir, cuando las leyes no respetan los derechos naturales, o el Estado se extralimita en sus funciones y dicta leyes que van más allá de los poderes que se le otorgaron en el contrato social, ésas leyes son injustas. He aquí pues, lo que según el pensamiento liberal debe entenderse por justicia: "Libertad contractual", o contrato que asegure y proteja la libertad individual. Algo completamente distinto al viejo ajustamiento natural"33.

\subsubsection{Justicia liberal desde la voluntad general.}

La tendencia contractualista resurge con Rousseau, replanteando un «buen» contrato, que renueve la construcción de la sociedad civil asentada en el «mal» contrato, perverso y dañino para los sociedades históricas que institucionalizaron la miseria, la comupción y el vicio, alejándose de marcar el progreso en la historia de los hombres. "Cuando prevalece la voluntad de todos sobre la volunlad general, se enseñorea de las colectividades la desigualdad que origina el amor propio. Esta es la triste realidad que nos demuestran los contratos históricos. Por el contrario, cuando la voluntad general vence, nace una verdadera república, una auténtica comunidad fundada, en tanto que comunidad, en la igualdad y en el amor de sí y el amor a los semejantes. Por la voluntad general el hombre pierde "su libertad natural y el derecho ilimitado a todo lo que el tienta y él puede alcanzar", pero conquista «la libertad civil y la propiedad de todo lo que posee«, además de la libertad moral, "que es la única que hace al hombre verdadero dueño de sí mismo». Mediante la voluntad general el hombre se eleva moralmente sobre su propia estructura lísica. El hombre físico deja paso al "hombre moral". Es entonces cuando puede hablarse de "justicia" 34

\section{I.7.4. Justicia liberal desde el imperativo categórico.}

En Kans, la concepción de lo justo arranca desde el apriorismo de la ley universal y necesaria como norma de conducta que conserva su calidad de ser norma práclica de por sí en cuanto no tienc la necesidad de recurrir a otros fines separando sagazmente el imperativo hipotético utilizable como medio para otros fines, del imperativo categórico como fin en sí mismo: "obra de modo que la máxima de tu voluntad pueda siempre valer como principio de una legislación general» es la famosa frase kantiana que negativamente transfigura a la justicia cn un ambiente exclusivamente formal, desvistiéndola de todos sus contenidos. "Al desnudar a lo justo de su contenido, al relegarle a mera forma, kant termina por ver en el ser jurídico una escueta forma de convivencia: la que garantiza la 
Libertad. Lo que equivale a arrancar del Derecho el valor justicia para dejarlo apenas en el exclusivo valor de seguridad"35.

\subsubsection{Justicia liberal anárquica.}

En recientes décadas( 1974) el liberalismo se coloca en la cumbre con Nozick (hasta cierto punto con una reelaboración contemporánea del pensamiento Lockiano) con argumentos que a muchos hacen temblar ante sus estremecedoras sustentaciones de la justicia. Nozick considera justo solamente el Estado mínimo, aquel que se limite a la protección de los derechos individuales de los ciudadanos. salvaguardándolos de las probables violaciones que puedan ser objeto éstos. El Estado sólo se justifica para la protección de la violencia, robo, fraude; un Estado más extenso violaría los derechos humanos de las personas a no ser obligados a realizar ciertas cosas. El aparato coactivo del Estado en definitiva, no puede obligar a los ciudadanos a que ayuden a otros o a prohibirles a las personas actividades para su propio bien y protección ${ }^{36}$. Según Gracia, "Nozick piensa que la moralidad no se reduce a la justicia, y que por ello su teoría libertaria de los derechos individuales debe complementarse con una teoría libertaria de las vircudes. Aquí cobra toda su pertinencia la distinción entre justicia y caridad. Y aunque la justicia afirma que nosotros no estamos obligados a contribuir con el bienestar de otros, la caridad nos manda ayudar a aquellos que no tienen derecho a nuestra ayuda" 37 .

\section{J.7.6. La Justicia igualitaria.}

La justicia toma terrenos libertarios, desde la libertad. En otras ocasiones la justicia es llevada hasta terrenos de la igualdad total y es Marx el principal ponente. Marx lleva la justicia al terreno económico, ya que ésta, más que ser un terna de tipo filosofico, tiene que ver con las relaciones de producción y en la forma de como estas se organicen y ordenen. Tiene que contemplar el modo de producción y la apropiación de los bienes que se producen. La desigualdad que se fomenta con tales tipos no permite determinar a la justicia según sus necesidades, sino una justicia que en el pensamiento liberal se convierte en lo que «es propio». La justicia que está en los liberales desatiende las capacidades y necesidades de los individuos, violentando el trato a los seres humanos como seres concrelos, principalmente por medio de uno de los mecanismos ocupados para dominar: el derecho. Por tanto, según Gracia "... como todo esto es injusto, según acabamos de ver, toda apelación al lenguaje de los derechos también lo es. En la sociedad comunista los derechos desaparecerán. También desaparecerá el propio concepto de justicia, pues cuando no existe la competencia por hacerse con bienes escasos, entonces, como Hume afirmó, la propia idea de Justicia deja de tener sentido 38 .

\subsubsection{La Justicia como equidad:}

Para finalizar solo nos queda brevemente exponer el máximo exponente de la 
teoría de la justicia de los últimos tiempos que se ubica entre las tesis intermedia de igualitarismo y liberalismo ${ }^{39}$, proponiendo la fórmula de la justicia como equidad.

La justicia como equidad trata de integrar las libertades civiles y políticas con los derechos económicos y culturales, partiendo de una idea de estructura social conformada por dos partes. El primer principio se aplica a una parte y el segundo a la otra. "Así distinguimos entre los aspectos del sistema social que definen y aseguran las libertades básicas y los aspectos que especifican y establecen desigualdades económicas y sociales. Ahora bien, es esencial observar que las libertades básicas se dan a través de la enumeración de tales libertades. Las más importantes entre ellas son la libertad política (el derecho a votar y a desempeñar puestos públicos) y la libertad de expresión y de reunión; la libertad de conciencia y de pensamiento; la libertad personal que incluye la libertad frente a la opresión psicológica, la agresión física y el desmembramiento (integridad de la persona); el derecho a la propiedad personal y la libertad respecto al arresto y detención arbitrarias, tal y como está definida por el concepto de Estado de Derecho. Estas libertades habrán de ser iguales conforme el primer principio"40.

"El segundo principio se aplica... a la distribución del ingreso y la riqueza y al diseño de organizaciones que hagan uso de las diferencias de autoridad y responsabilidad. Mientras que la distribución del ingreso y de las riquezas no necesita ser igual, tiene no obstante que ser ventajosa para todos, y al mismo tiempo los puestos de autoridad y responsabilidad tienen que ser accesibles a todos. El segundo principio se aplica haciendo asequibles los puestos $y$, teniendo en cuenta esta restricción, disponiendo de las desigualdades económicas y sociales de modo que todos se beneficien.41

Los dos principios de Rawls se resumen de la siguiente forma:

1. Toda persona tiene el mismo derecho a un esquema plenamente válido de iguales libertades básicas que sea compatible con un esquema similar de libertades para todos.

2. Las desigualdades sociales y económicas deben estar asociadas a cargos y posiciones abiertas a todos en igualdad de oportunidades; y en segundo lugar, deben suponer el mayor beneficio para los miembros menos aventajados de la sociedad42.

En este esquema Rawls diferenciará tres principios más:

I. "En las libertades civiles rige el principio de igual libertad de ciudadanfa.

2. Los cargos y posiciones deben estar abiertos a todos conforme al principio de justa igualdad de oportunidades.

3. Las desigualdades sociales y económicas (poderes y prerrogativas, renta y riqueza) deben cumplir el principio de la diferencia, según el cual la distribución 
desigual de esos bienes sólo es justa o equitativa si obedece al criterio maximun, es decir, si ninguna otra forma de articular las instituciones es capaz de mejorar las expectativas del grupo menos favorecido"43.

De lo anterior Rawls obtienen las reglas de la "prioridad». Que se explican en una relación preferencial del primer principio básico sobre el segundo básico; y de los principios que se observan en el segundo bosquejo de la exposición, opera una relación de preferencia del primero sobre el segundo y estos sobre el tercero, así establece la regla de la prioridad:

1. La prioridad de la libertad, formulada como: «las libertades básicas sólo pueden ser restringidas en favor de la libertad en sí misma»

2. La prioridad de la Justicia sobre la eficacia y el bienestar, con lo cual se afirma que la igualdad de oportunidades es anterior al principio de la diferencia44.

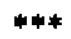

Como hemos observado a lo largo de toda esta exposición la justicia ha tenido un largo recorrido teórico, que puede seguirse puntualizando con otros autores. Sin embargo, hemos intentado presentar los autores más relevantes e influyentes en su conceptuación (los que la afirman, y no tanto los que la niegan). Con esto se presenta hasta cierto punto una especial historia. Historia política e historia concreta de la idea de la justicia. Esperamos que nuestra primera pretensión de ver lo formal, y algunos posibles contenidos de la justicia en el presente trabajo hayan satisfecho en manera alguna las principales exigencias que de ella se han denotado. Talvés quien haya seguido las líneas escritas hasta este punto notará, que probablemente hayamos sido demasiado extensos en el apartado, de lo cual estamos conscientes. Sin embargo, este capítulo de la idea de la justicia representa prácticamente la apertura hacia la comprensión de la justicia en nuestra Constitución, al mismo tiempo es el paso esencial para saber como desde el nivel axiológico podemos situar una idea que combina el transcurrir de los matices que se han dado de lo justo. No obstante lo anterior, si de combinar se trata, y estrechar lazos conectivos con el derecho, tenemos que hacer referencia a otro punto muy importante en el tratamiento de la justicia. Un tema que nos sitúa con mucha más cercanía a lo jurídico, y que se vuelve de vilal importancia; y es el que discutiremos en el apartado siguiente.

\section{La Constitución.}

\subsection{La Constitución como matiz esencial en la Justicia.}

La historia es una tonalidad que representa una zona atendible en la planeación de cualquier organizador y planeador que se tome en serio su papel. El estratega 
político y el militar la rescatan al visualizar sus decisiones futuras. El administrador de la cosa pública, y el gerente de la cosa privada delinean así sus estrategias para no repetir, si eso es lo querido, los errores del pasado. De esta manera, la historia vuclve a jugar un papel preponderante e indefectiblemente nos proporciona hechos relevantes que reviven en el derecho. $Y$ que al mismo tiempo dan su toque para decirle al legislador y al constituyente lo que han de hacer, porqué lo han de hacer, para que lo han de hacer, y donde y cuando han de hacerlo. Pero así como en la historia, y en ella inmersa la justicia, existen elementos que el jurista no olvida ni desatiende, máxime si el componente es crucial para realizar su labor científica y su tarea práctica; también en la creación de las distintas normas fundamentales que dan base a todo el ordenamiento jurfdico de un Estado determinado se delatan elementos cruciales. El basamento teórico y práctico en ésta instancia cuando se hace un análisis desde el derecho, en el derecho, y junto al ordenamiento jurídico y que el jurista no puede con simplezas apartarlo es la Constilución.

\subsection{Constitución y regulación: el primer paso de lo justo.}

La Constitución vista así es un presupuesto inicial de donde se retoma los pilares básicos que sostienen el ordenamiento jurídico. Es una especie de sostén que acredita en sus enunciados normativos la presencia de las normas fundamentales 45 . Cobija en ésta forma la organización del Estado, creando y cerciorándose de la construcción jurídica de una serie de instituciones básicas en el quehacer estatal; da cobertura a una serie de derechos que han venido siendo conocidos como derechos constitucionales; y da también reconocimiento y protección en su seno a otro apartado de derechos que por su crucial importancia para la persona han venido siendo enunciados por medio de la expresión de derechos fundamentales. Hasta aquí, en resumidas cuentas, la Constitución nos presenta: " los derechos, su declaración en primer lugar; las garantías,su establecimiento, en segundo; los poderes, su constitución, lo tercero, con el requisito preciso finalmente de su constitución plural y separada" 46 . La Constitución es eso, pero no lo único. Aún nos falta manifestar que también dentro de la misma se da forma a lo que son los fines del Estado, concretados en unos valores que en nuestra realidad, son los que deben protagonizar el obrar del Estado Salvadoreño: La justicia, la seguridad y el bien Común. Y la dignidad de la persona Humana como valor principal47. Estos últimos no significan otra cosa que la impronta de dotar de características jurídicas a una surna de elementos que el pueblo ha venido considerando en sus ideas como metas alcanzables. Se plasma así en la Constitución una especie de élica que respalda la labor normativa, sin entrar en actividad de desdoblamiento con los actos juridicos. Así vistos los valores de la justicia, la seguridad y el bien común sería en las palabras de Canales el punto al que ha llegado "la fiebre reconstructora y la pasión normativista que embarga a los constituyentes de los últimos decenios, [que] ${ }^{48}$ dentro de nuestro ambiente cultural, 
mueve también el ethos de los juristas, en manifiesta y confesada intención de dar eficacia normativa a aquellos ideales, ahora plasmados en formulaciones amplias, quc adoptan la denominación de fines, valores, principios" 49

\subsection{La adaptación de la Justicia en la concepción de Constitución: la reali- dad.}

Manejar una concepción de Constitución debe ser enfática en el especial compromiso definitorio. Hacer lo contrario nos haría caer en ligerezas: como las que se cometen desde un escepticismo radical al señalar en sus discursos que la Constitución está basada en el error, o que es un instrumento pervertido, inútil y obsoleto50; y con una atenuación de lo escéptico pero radicalmente positivista al cnunciar que la Constitución es "la letra negra impresa en la norma fundamental". Sin duda, la concepción de una constitución no debe ir por la negación de su existencia. La Constitución está presente, y actúa desde el plano global normalivo que autoriza. No es perversión, ni solo norma escrita, es en especial, una rcalidad jurídica que estabiliza y asume el consenso (dando cabida desde luego a disensos) de lo querido por un pueblo. Si el pueblo la quiere la legitima, si no la transforma o crea una nuevası.

El punto es que debemos alejarnos de ver las Constituciones, así como hemos venido diciendo de la justicia, como un muestra única de lo formal. Las Constituciones se identifican con instrumentos, con papeles, con páginas forradas de azul y blanco. Se igualan a derechos escritos en una librito (hoja de papel, Constitución (ormal) que todos los políticos, legisladores y jurisconsultos nos señalan como rector. En verdad es algo diferente. $Y$ lo que hace diferente a una concepción objeto es el aspecto material. Son sus contenidos que regula. Son las materias que preestablece desde la propia realidad52 y consecuente con los valores fundamentales. La realidad debe apegarse a la norma, y la norma debe de apegarse a la realidad, ya que lo que se trata es de regular escenas reales y no ficticias. Lo que se intenta es activar las zonas de la realidad y darles vida en el mundo jurídico. Evitar este consejo llevará al legislador y al resto de operadores jurídicos a producir decisiones que se vuelcan como inútiles, y que envés de amortiguar el conflicto lo acrecientan ante la falta de compromiso con las reglas del juego, ya que estas se muestran irreales, y epigenéticamente desligadas de lo que sucede en la vida cotidiana. En este orden de ideas Martínez García es muy claro en su advertencia cuando se construyen las ficciones en el derecho ante la utilización de la técnica de los escenarios fícticios: "véase de no crear selectivamente y desactivar zonas de realidad como si no existieran"53. El profesor Pablo Lucas Verdú será insistente en el punto al asumir la herramienta correctiva de la realidad contra el papel reductor que en la tradición jurídica ha venido desempeñando la corriente de lo positivo en la explicación del funcionamiento del derecho y de los ordenamientos jurídicos. Al efecto, es llamativo su discurso en cuanto "que la Constitución es incomprensible, si por naturaleza metódica o por exagera- 
ción del método técnico jurídico, método que corrige en gran medida al positivismo legalista precedente, ignoramos la realidad social [concordancia entre Constitución Real y Constitución formal]54. Esta realidad social opera como contrapunto de la normatividad. Es decir, se compone de exigencias socioeconómicas, de puntos de vistas sobre la libertad, igualdad y el pluralismo político" que para nuestro caso se compondría de puntos de vista sobre la justicia, seguridad y el bien común 55 .

En vista de lo que antecede la realidad es una fuente constitucional. La realidad le imprime a la Constitución una especie de fuerza dinámica y posibilita su evolución. Por ello el legislador o el constituyente debe observarla siempre, y recogerla cuando es debido. El Constituyente no debe bifurcar la realidad imprimiéndole un cariz estático, sino dotarle de movilidad y estar siempre a la altura de los tiempos.

Con el tema del tiempo la Constitución se retoma la realidad, y resulta Iógicamente que ésta no es inmóvil. De ahí, que se necesila una cierta y cuidadosa temporalización de los conceptos que pueden estar implícitos en una Constitución. Decir un no al faclor tiempo significa ingenuamente una atemporalización, la que ahonda en la deslegitimación popular, restablece un positivismo moderno (y no contemporáneo) reductor de la vida constilucional al letrificamiento textual y corpóreo constitucional, y finaliza eliminando cualesquiera consideraciones históricas, políticas o filosóficas, aparte de aunar los esfuerzos para un conservadurismo patológico de lo político. El factor tiempo en las consideraciones constitucionales sujetan a la Constitución en una apertura de posibilidades, en una especie de necesidad en la adecuación de la norma para conciliar la realidad presente, la del momento y tener en cuenta los supuestos de una realidad futura56.

¿Pero cómo temporalizamos la Constitución?. La justicia junto a otros valores fundamentales serán determinantes en este aspecto. Por medio del combustible que puedan proporcionar a la Jurisprudencia, al legislador y al resto de operadores desde una concepción valorativa, jurídica y constitucional. Una concepción que a la vez asume un espíritu juzgador frente a lo que sucede y que puede ser de utilidad en las conductas a regular y derechos a reconocer. Uscatescu evocando a Carl Schmitt es significativo al presentamos que "la interpretación jurídica y científica de la Constitución no puede avanzar, sin un claro sentido crítico de la historia, so pena de caer en un formalismo insustancial y en una palabrería vana57"

\subsection{Una síntesis constitucional en torno a la Justicia.}

¿Qué es lo que tenemos entonces después de toda ésta serie de advertencias en torno a la constitución?. Evidentemente, lo que se presenta es que la Constitución tiene una realidad, está hecha en un tiempo, tiene definida una estructura de derechos y garantías, como también la constitución de unos órganos que constituidos reelaboran el quehacer estatal conforme a las pautas de la legalidad, 
división de poderes y respeto de los derechos fundamentales. A su vez existen unos valores reconocidos juridicamente. $\mathrm{Y}$ al mismo tiempo entre esos valores está la justicia. La justicia en primera instancia está unida a la constitución, y está amarrada a los otros valores, en especial a la dignidad humana como fundamentador de la misma justicia, de la seguridad y el bien común.

\subsection{El presupuesto axiológicosB de la Justicia en la Constitución como pun- to de partida.}

Ahora bien, la Constitución es ya un buen punto de partida par delinear un visión justicia en la Constitución, el papel que esta juega es preponderante, como lo es el de los llamados a hacerla práctica y eficaz. En esto entramos al mismo mundo, al jurídico constitucional, pero le damos vuelta al perímetro que la justicia constituye. Es importante lo constitucional, y no menos importante es el aspecto valorativo que la justicia comporta. La presencia de la sustancialidad axiológica en las normas imprimen así un factor adicional para brindar más explicaciones de la justicia y mostrar la virtud de que es posible hacerla accionar como dato empírico, especialmente si la mayoría supone que el ámbito de la ética y de la axiología desde el punto de vista del derecho es un campo que nada liene de relación con la experiencia o con el mundo práctico.

En lo que sigue nos detendremos en la valoración conceptual de la justicia; es decir, en su realidad valorativa que depende y hace depender de ella la racionalidad de la realidad normativa constitucional y que al mismo tiempo se estampa en consonancia al mundo de lo que es posible ejercitar. Hablamos por tanto de un especial entronque de la justicia con la experiencia, del mundo valorativo abstracto y general con el mundo valorativo empírico y real, de la ética junto al hombre, de la justicia como valor y exigencia que en términos jurídicos puede ser cumplida. Con ello presenciamos las palabras de Frondizi cuando expresa que "la experiencia no queda excluida pues del campo de la élica y la teoría de los valores. La ética aspira a regular la conducta del hombre, que es un hecho empírico, y la axiología se reliere a valores incorporados en bienes que también son hechos empíricos. De ahí que no se puede volver la espalda a la experiencia. Una norma carece de sentido si no se puede cumplir; el de deber supone poder cumplir con la exigencia. Y ésta es la cuestión empírica"s9

\section{Valoración conceptual de la justicia}

\subsection{Enfoque general de lo valorativo en la Justicia.}

El mundo de los valores, por lo general sitúan al individuo que los interpreta en concepciones de importancia, de lo que él quiere, de lo que le reporta en última instancia fclicidad, autorealización. Cada ser humano tiene o acepta una tabla de valores, que en conjunto pueden ser una mezcla de números, en cuanto 
lo que valen las cosas, un sentido religioso, en cuanto alcanzar la santidad, un sentido de lo estético, en cuanto alcanzar la belleza, y en cuanto equilibrio, a la justicia.

Estas tablas de valores no siempre son perseguidas por todos los sujetos, habrán unos que sus valores estarán en la maldad y no en la santidad, en la fealdad y no en la belleza y en la injusticia y no en la justicia. Esto nos dice que los seres humanos tienen diferentes tablas de valores, que los seres humanos priorizan algunos, por multitud de circunstancias que no vienen en este momento discutirlas. Y que en síntesis los valores representan diferentes mundos, lo individual, lo que percibo desde la propia individualidad personal; al mismo tiempo los valores esbozan colectividad y un interés general60. Para el derecho y la perspectiva que seguimos es ésta última línea que se renueva en el quehacer estatal. Cuando persigue unos valores constitucionalmente reconocidos está en primer lugar hablando desde lo general, y desde lo querido para la colectividad. Así el Estado salvadoreño sin desconocer las propias individualidades de sus sujetos y la dignidad humana, esperanza en su formalismo constitucional a la justicia.

Advertimos que no hay que confundir que la justicia que se pretende analizar sea siempre perseguir el interés general en detrimento del individual, sino el conciliar los dos a su vez y las ganancias sean obsequiosas para ambos. La operación no es interés general, eliminación y violación del interés individual sino la vivencia armónica de ambos. La sala de lo constitucional en este orden ha incluido en su pronunciamiento que "... no caben interpretaciones que sacrifiquen el interés de la sociedad en beneficio del interés egoísta de un individuo,pero tampoco puede sacrificarse totalmente uno sólo de los derechos de las más modesta de las personas en aras del interés social. Lograr la justa armonía debe ser la función del legislador y sentenciar sobre su cumplimiento es deber de este tribunal"6/2

En consonancia a lo que precede, sin ser textuales y retomando las palabras de Alexy cuando explicita la ley de la ponderación, de lo que se trata es de medir la importancia que debe concederse a «ellos», y de lo que no trata es de encontrar que tan grande es la importancia de «uno de cllos», lo que conlleva la ponderación no es una cuestión de todo o nada, sino una tarea de optimización. Es una especie de medición de grados, del grado de insatisfacción de uno y el grado de satisfacción del otro62. Ante esto a la vez hay que estar atentos de nuevo por una posible caída en terrenos peligrosos ya que la justicia es un valor que se realiza en el Estado y que la íntima relación entre éste y el gobiemo tendrá mucha influencia en que se fundamente la justicia en función de los hombres (ideologías) que detenten el poder; sin embargo, de este peligro sólo podemos salir en la medida que el Estado evolucione a transformarse en un medio y no en un fin, o valor o la identidad con una filosofía.

Es creible que no es inútil insistir a continuación que al retomar en este 
trabajo la justicia como valor, esbozando su ambientación conceptual, tiene que ser asumida no desde lo que es justicia para cada ser humano, eso es justicia aislada, peligrosa por el margen y multitud de derivaciones conceptuales que origina63. En el pensamiento jurídico de Stammler se resalta ya este modo de abordar los conceptos, las apetencias, y los pareceres "la afirmación de que las opiniones y los deseos meramente subjetivos constituyen la medida de todas las cosas, no puede ser tomada en serio. Si fuese asI sería imposible convencer a nadie de un ertor" 64 .Tiene que ser asumida por tanto desde una óptica consensual retomando las enseñanzas de Protágoras al asumir la justicia como decisión en estrecho contacto con la voluntad de la comunidad. Pero hay que advertir que a la hora de retocar el tema del consenso el matiz que debe estar en el discurso, es el de dotar de cabida a los disensos (a través de los diferentes mecanismos establecidos por el ordenamiento jurídico, voto, representación, consulta popular, instancias y recursos en el campo jurisdiccional) ya que si no, estarfamos entrando al concentrar el consenso como decisión única de la comunidad estatal, en una especie de totalitarismo colectivo; meta final que debe ser cuidada de no lograr en el presente, es decir, para las generaciones actuales, y a su vez cuidada de no hacerla realizable para las generaciones futuras al negarles mecanismos de decisión que puedan retroalimentar o regenerar la idea de lo justo aceptado en una etapa generacional anterior, con ello destacamos otro presupuesto básico que liene que ser asumido dentro de un proceso que «puede ser destacado como reversible» si así fuera necesario, "y generalizable» (para esas generaciones nacidas y por nacer, sino estamos en lo estático, en lo inmóvil y lo petrificante).

\subsection{El valor jurídico constitucionalizado.}

Asf́ los presupuestos anteriores, la Constitución salvadoreña reconoce unos valores de primer orden, la justicia, indiscutiblemente está entre ellos. La justicia es un valor, que revive en el derecho constitucional. Un valor que ha dado el paso de lo que antes pudo haber sido, o sea una simple moralidad alejada del canon normativo jurídico, logrando ahora, la conversión en una ética jurídica de tipo normativo, es decir, en una moralidad que está legalizada según el profesor Peces Barba, y que al estar legalizada no significa la destrucción de lo que en primera instancia era, es decir un valor:" en ese sentido creo que hay un prius, los valores, que recoge el núcleo de la moralidad de la modemidad y que sc incorpora al Estado Social y democrático de Derecho, como moralidad política y con su impulso se convierten en valores jurídicos". 65

En cste sentido, la justicia ha sido adoptada por el constituyente, diríamos, por considerarla como un ser valioso que todo humano en condiciones normales anhela para su vivencia societaria y algo provechoso que en condiciones anormales se anhela aún más para el perfeccionaniento la vivencia social. De aquí es de suponer, que la justicia no es un ideal irracional, sino una idea regulativa para lograr algo, y no simplemente una noción de algo66. La justicia busca así 
reflejarnos desde la norma constitucional el hacia donde vamos; siguiendo la exposición del profesor Skolimowski, se nos refracta el "plus» de la tradición axiológica de los hombres occidentales, entre los cuales la reverencia por la vida, la responsabilidades, la compasión y la justicia tienen que ser asumidas por todos y para todos. Ya no sólo es honor, valentía y sacrificio personal como en los griegos: ni es sumisión y piedad como en los cristianos, ni únicamente humanismo y simplemente autoconformación y cumplimiento como en los renacentistas, ni eficacia, o poder sobre las personas como lo refleja la vida tecnológica67. La justicia en Skolimowski, es el ultimo agregado de nuestra era, cn cuestión de valores, lo que presupone junto a nuestra ideas que es el indicativo orientador del plan, organización, y soluciones a seguir, sin embargo, Skolimowski, no explica sólidamente la exclusión de la justicia en los ordenamientos anteriores, en los cuales la justicia como la libertad han estado presentes, aún cuando fundamentados en regímenes políticos en que el principio de igualdad no se concebía, por lo que tanto la justicia como la libertad, eran valores aplicables a los individuos de acuerdo a la pertenencia a una clase social.

La justicia se adopta por el constituyente, otro momento será si la vida diaria refleja todo lo contrario: La injusticia. La cual parece ser ha sido el común denominador en aquella historia que todos conocemos pero que parece olvidarse bajo el apadrinamiento del perdón. En esta forma recordemos de como en aquel pals de los ensueños la mayor parte de la población estaba en un contexto de inseguridad. Inseguridad en tanto, no sabran si en la práctica poseían derechos, y si ésos derechos los podían hacerse valer, digamos en concreto "ejercer". Se ha dicho para el caso, de como la mayor parte de los habitantes de ésa República habían estado en un constante abandono, a tal grado que la vida y la integridad física principalmente, por no mencionar otros derechos, se habían convertido en algo superfluo, en consecuencia, en derechos que a pesar de estar reconocidos constitucionalmente, se expresaban en la práctica como mandatos inexistentes. ¿ Era injusto?. Cualesquiera que tuviese un mínimo de recato moral, tendría que asumir una posición positiva. Y cualesquiera que asumiera la justicia como valor primordial a perseguir vería de como el antivalor se expresaba en el cuento que nos atañe. Por ello volvemos con la interpretación constitucional, la justicia es un valor que está en la constitución y debe permilir su práctica como valor en la realidad. Creemos que ésa es la máxima ventaja de la justicia y su vez su peor desgracia, en el ambiente jurídico. Sin embargo, dotarle de una apertura hacia el exterior del ordenamiento jurídico hará más grande las posibilidades de acercamiento a lo real, a lo que el pueblo valora como justo (en esta idea hay que desechar una posible formación de la justicia hacia un tipo de concepción demagógica). De no haber sido así, no tendríamos en la última década la enorme cantidad de reformas constitucionales y revisión de las leyes que rigen nuestro Estado. En el fondo parece estar latente la justicia. Implícitamente está escondida en toda la rcestructuración de nuestro ordenamiento, aunque aun falte mucho por hacer... 
Retornando con el planteamiento debemos tener claro, que la justicia es un valor. Es decir, es una cualidad, y al mismo tiempo es una esencia de tipo objetivo que encontramos en la realidad cultural. Así como encontramos la belleza, así como podemos proyectarnos la elegancia, también podemos descubrir la justicia68 en el entorno social y en la vida jurídica demarcada en primera instancia por el perímetro constitucional. Esto nos indica que la justicia no puede darse en forma abstracta, siempre requiere conductas y términos de comparación entre sí o ideas que iluminen los patrones culturales de un comportamiento deseable.

\subsection{Caracterización valorativa de la Justicia en la Constitución.}

La caracterización de la justicia desde el matiz de la norma fundamental lleva consigo una presentación elemental, esta es la que se refiere a los rasgos comunes que hemos de encontrar de ella en nuestro mundo contemporáneo. Con ello mostramos los elementos esencialísimos en la explicitación de la justicia como un valor. Es decir, cuales son los atributos identificativos que se requieren para que estemos en su presencia, tanto en su idea valorativa como en su dato empírico:

\subsection{I.Está encarnada en un objero cultural juridico fundamental.}

En primer lugar se menciona que tiene que tener la posibilidad de una realidad en la que pueda encarnarse. Es decir existe la necesidad de considerarla como no independiente de los seres y de los actos en los cuales se realiza. Por ende necesita de los objetos culturales 69 como punto de referencia para considerar si reúne la cualidad de ser justa. De esla manera la justicia le podemos encontrar encarnada en el fundamento de los ordenamientos jurídicos. Le podemos encontrar plasmada como es el caso nuestro en una Constitución. Y veamos que no es un simple reconocimiento, sino algo superior, que le revisle de mayor valiosidad que las propias conductas que se pretenden regular formalmente. Es decir, es el fundamento del orden, es la justificación del actuar, es la razón de Ios seres. Con lo que la justicia adquiere la validez formal para ser adoptada por los seres que realizan, ejecutan, aplican interpretan y obedecen las normas jurídicas, los principios y valores generales y superiores en el ordenamiento. Sin embargo, esta pauta no la llevemos hasta un sobredimensionamiento que nos lleve a una hipertrolia del concepto. Por lo que es conveniente identificar el valor ante realidades concretas.

\subsubsection{Un carácter interaractuante con otros valores.}

Pero téngase muy en cuenta que si bien es cierto la justicia representa un fundamento reconocido constitucionalmente, no es el único, por tanto no es absoluta. Si no lo es, hemos de encontrar que la justicia debe dejarse auxiliar en su papel por el valor seguridad y el bien común reconocidos en la misma forma en nuestra constitución. Es una tarea de ensamblamiento de valores. Ya que los 
mismos no podrían verse en forma aislada. Cada uno de ellos hay que advertir tiene un ámbito material que le es propio, por lo tanto diferente. El supuesto en el que es peligroso incurrir es el verles en forma aislada y situarles en el paraje de lo solitario. Las distinciones entonces que encontramos en sus contenidos no dan pie para guardarlos y sacarlos cuando el interés ideológico dominante o crítico ha de utilizarlo. Siempre están presentes, formalmente y vivencialmente en la articulación constitucional. Su vida, y digamos correctamente su vigencia, está en la electividad de traspolarlos y engarzarlos con el valor que discutimos. Diríamos que la justicia en este sentido así como va «indisolublemente unida a los derechos humanos» 70 también lo está con el resto de valores anteriormente mencionados. En el mismo orden de ideas la exposición motivos de nuestra Constitución remata lo que venimos diciendo del carácter interactuante de la justicia con los otros valores, así dirá que“... Por eso la escogencia de los tres grandes valores: justicia, seguridad, y bien común, que en un mismo orden jerárquico se consideran complementarios y no antagónicos, como más de al iusfilósofo ha sostenido. No puede haber justicia sin seguridad y el bien común no puede garantizarse sin el concurso de aquéllos otros dos valores"71

\subsubsection{Bipolaridad.}

En tercer lugar, se suele presentar con el carácter de la bipolaridad, es decir con un opuesto correspondiente. Así como el bien se le opone el mal; a la vida, la muerte; al dolor, el placer; a lo masculino, lo femenino; a la justicia se le opone la injusticia. Claro, que la utilización de este carácter no debe ubicarnos de nuevo con un simple operación intuitiva, emocional, y despistada de los otros elementos que auxilian a mostrarnos el valor práctico a instalar en la realidad social vía labor constilucional. El mecanismo de la bipolaridad no es decir, como mucha veces sucede en el desconocimiento popular, de si es negro, no es blanco, si es negro, por tanto es injusto, y hay que buscar la blancura, y la resplandecencia de la justicia por oposición, haciendo gala de las respuestas totales y completas que la intuición nos presenta. Charles Handy nos ilumina en el punto al afirmar que "incluso la ciencia [natural]72 no conoce respuestas perfectas, ni cree que puede haber alguna. Dada esta premisa, uno tendría que ser muy arrogante, muy estúpido o muy insensible para afirmar que conoce la verdad completa de algo en forma anticipada"73. En otras palabras, la bipolaridad de la justicia implica por medio del patrón de lo que está en el opuesto, un análisis, que no es "simplemente identificativo, y solucionador", con ello lo que pretendemos por medio de una bipolaridad en el valor justicia, es sólo un primera instancia de visualización de lo que «sucede», para no abdicar, y utilizar los mecanismos, procesales e instrumentales adecuados, para la plena realización del valor.

Veamos un ejemplo palpable. Se habla de delincuencia. Los periódicos publican homicidios, y no simples homicidios, sino a atentados contra la vida 
repletos de agravantes delictuales. El periodista y el ciudadano estigmatiza el hecho como cruel, como una conducta sin discusión injusta. Ahora veamos, la operación de limpieza, si es así como debería ser, indicaría máxima sanción. El dato solucionador es simple en esta inclinación, incluso habría unos que se la tomarían por su propia mano. La respuesta de lo anterior, no es injusticia, y el «out put» justicia. Hecho delictual agravado, y sanción del hecho punitivo agravado (téngase bien que puede haber absolución y eso también es justicia). La operación de la práctica de la justicia no es tan sencillamente reductiva a un simple enlace operativo mecánicamente. ¿Y por qué no?. El derecho, el ordenamiento jurídico en concreto, no es una máquina que indefectiblemente saca el producto bajo funciones de sumas y restas que dan un resultado exacto. No es un aparato que construye objetos inanimados, menos productor de seres vivos con los mismos rasgos físicos. El derecho no busca la exactitud, ni lo inexacto, el derecho pretende el acercamiento hacia la "certeza" alejándose en lo más posible de la incertidumbre que nos proporcionarían interpretaciones contrarias al ordenamiento jurídico o bien de la ausencia de reglas y principios que terminan desbaratando a éste. Por esto y otras razones el derecho y especialmente cuando estamos en presencia del ordenamiento jurídico primario, es decir el constitucional necesita, urge, exige y obliga a utilizar un método para la interpretación y lograr la certeza. Exige la aplicación y la interpretación de un sistema, y no de cualquier sistema, sino de un sistema de normas previamente establecido y acordados a través de los canones consensuados por la sociedad civil que ha legitimado la formas de prevenir, la injusticia y rehabilitar la justicia.

En el caso de las conductas delictuales, se exige investigación, se garantizan derechos fundamentamentales del imputado, y se le da la oportunidad para el esclarecimiento del hecho conforme los patrones normativos establecidos por el derecho penal (sin dejar de lado el constitucional). Esto en teoría, otra cosa será, si nos volvemos en forma crítica hacia nuestro sistema especialmente el penal en donde la justicia se diluye en multitud de deficiencias que no hacen otra cosa que disminuir la posible infabilidad del orden penal, cuando este ha llegado al momento de dilucidar efectivamente si el supuesto imputado es merecedor o no de la gracia absolutoria o de la desgracia de una condena.

En resumen, la justicia se expresa en la bipolaridad, esto es ya un rasgo muy importante de su valor. La tarea que implica es formalizarse, y materializarse en un método de contraposición. Es decir, es la búsqueda de los diferentes polos, el positivo y negativo de la acción que se evalúa como injusta o justa. Sin embargo, ésa búsqueda de la positividad o de la negatividad en los extremos de las circunstancias o situaciones que son objeto de evaluación o interpretación debe pretender como bipolaridad ser sólo un primer paso identificativo, objeto de una posible reestructuración por los otros caracteres del valor, y por la metodología interpretativa de lo jurídico. La bipolaridad, es pues, un apuntalamiento parcial y no completo del caso. Parcialidad que es medida, cambiable o con posibilidad 
de ser corregida si la ayuda de los elementos que encontramos en otros sectores del derecho diagnostican su no idoncidad, como primer contexto visualizador.

\subsubsection{Intensidad.}

Conectada con la bipolaridad está la intensidad. La información vital de ella está en la fuerza y el vigor con que se activa la justicia. La mauifestación radica en la especialidad que posee para retocar lo que hemos de llamar «una variación de la intensidad en la variedad de situaciones que aclúa». Con lo cual tendremos que tener presente que no en toda circunstancia posee el mismo rigor, sino por el contrario, tenemos que ir adquiriendo la destreza necesaria de cuando la justicia necesita de una menor intensidad para mediar en el orden justo y una mayor intensidad cuando presencic con claridad la injusticia. Esto no debe conducir a que la justicia se debilita, sino a predecir que la justicia a veces se consagra con cierla pasividad y otras con mucha actividad, en ocasiones puede sentirse vehemente y en otras más potente. Es por ello que habría que admitir en este valor, la necesidad de los diversos grados de intensidad a que puede ser sometida en la acción. Esto para el caso lo tendríamos en "algunas ocasiones", en la preocupación igualitaria de los derechos sociales y la preocupación protectora y a la vez restricliva, "algunas otras veces», de los derechos típicamente liberales. En éstos derechos la intensidad que mencionamos cambia al admitirse un mayor afán de grado en la protección y quehacer positivo del Estado. En unos se vuelve más imperante en la corrección y en otros la justicia se vuelca más intensamente en el impulso protector por los desposeídos.

La situación que se presenta es una justicia que se «ajusta» a la realidad. Esta realidad de por sí se nos presenta como un todo que hay que ir descubriendo poco a poco, utilizando el método adecuado. El jurídico en primera instancia, que es el predominante cuando la justicia está en la constitución y es informadora del orden. Sin desligarse por supuesto del afán histórico, el cual más bien se adentra en una metodología de tipo historicista 74 y no simplemente histórica. La elasticidad, la maleabilidad, debe por tanto ajustarse a un contexto real, en el que no predominen los signos irracionales al concebirla. El primer error, señalaba Rickert al analizar la historia, es plantear que la realidad es uniforme. $O$ sea, que las conductas humanas que se plasman en una historia del hoy, del ayer o del mañana no son homogéneas, ya que el presentarla en distinta forma, y el no prescindir en el análisis de la homogeneidad, o bien el absolutizarla nos lleva a un planteamiento puramente irreal, en donde solo encontramos seres ideales. Por ello si el intérprete quiere conocer la realidad, si el interprete quiere asumir las cualidades que observa y que se adhieren a su pensamiento e intelección debe atenerse a la heterogeneidad75. Así la realidad es racional y no ideal, y así la juslicia termina amoldándose al cambio, a la mutabilidad de la historia y no se convierte en un valor presa de la intemporalidad, ni finaliza su acción ajustando en el mismo traje a todos los ciudadanos 76 . No hacerlo en una perspectiva inver- 
sa nos llevará que para algunos la justicia les quedará demasiada holgada y para otros les supondrá una vestimenta estrujante y quizá asfixiante. He aquI en donde la elasticidad, el ajustamiento y no el «ajusticiamiento» caben para el logro protectivo de los que tienen menos y corrector de los que tienen mas influencia, más poder, y mayor congraciamiento con la justicia que niegan a los desposerdos, al dejarles morir en la pobreza extrema, $o$ al dejarles en condiciones infrahumanas de existencia.

La justicia en este sentido debe preocuparse más por las mayorfas populares77. En este sentido conectando con la jurisprudencia, y la definición de la actuación del interés social se ha dicho que: "... Sobre el particular, es necesario reconocer que no es lo mismo el interés del Estado o el interés del Gobiemo, que el interés social. El interés social a diferencia de los anteriores, tiende a satisfacer, por medio de medidas legislativas o administrativas, las necesidades que adolecen los grupos mayoritarios del Estado. También opera el interés social, cuando se trata de evitar algún problema que afecte o pueda afectar a dichos grupos; y habrá finalmente interés social en mejorar las condiciones sociales vitales de dichos grupos mayoritarios" 78 Con lo cual parece indicarse que se deba corregir en mayor medida a los que se sitúan a nivel de la superfluidad79. Máxime si estamos en un país en donde la estructura delata que los muchos siguen viviendo en condiciones que no satisfacen las necesidades básicas, en el que la estructura económica, política y cultural es evidente y grandemente desigual80. Con lo cual admitimos la urgencia de una preponderancia de la intensidad en la variedad. Es algo parecido en lenguaje común a un estira y encoge en el que predomina la adaptabilidad, como un concepto que en determinadas situaciones y circunstancias ponderadas y racionalmente justificadas permiten dotar de protección a los interesados. En este contexto hay que observar que la intensidad nunca debe convertirse en una intensidad ilimilada u absoluta, y por el contrario hay que ser cuidadosos con que la intensidad cuando sea menor, no termine convirtiendo el concepto de justicia en un algo «sin nada»81. El Tribunal Constitucional Español refuerza nuestra tesis cuando se pronuncia acerca de la justicia, al traerla en la interpretación judicial, por medio de la cual ésta no debe brindarnos un campo abierto hacia el infinito, ni mucho menos una franja vacía de consideraciones. La justicia así presentada está limitada, puesto que su concepto es un concepto limitado que no hay que vaciarlo de contenido, ni extenderlo ilimitadamente. ${ }^{2}$ De ahí, hay que sujetar la justicia a limitaciones, siendo éstas que no vayan a los extremos de lo relativo y que puedan dar lugar a interpretaciones arbitrarias.

\subsubsection{Jerarquía}

La justicia posee una jerarquía en el orden natural, y asimismo en nuestro ordenamiento la situación vuelve a repetirse. Advertimos que nuestra opción no es iusnaturalista, tampoco iuspositivista cerrada y estática. En verdad nos apun- 
tamos hacia una tendencia diferente al círculo vicioso del naturalismo, creemos que es más propicio la movilidad, mutabilidad, y cambio de la concepción según la exigencias permisibles, necesarias, proporcionales, ponderadas, justificables y racionales que el devenir históico presenta. Aclaración que está fincada en nuestro argumento. Ya que no hablamos de justicia natural83, ni de justicia simplemente legalista84, ni de justicia constitucional85, sino de la justicia en la Constitución. Desde esta aclaración hay que suponer que la justicia jerarquizada está en la Constitución como valor; ello no debe hacernos suponer que está un orden superior al constitucional. La justicia no es un orden superior, ni humano, ni divino sobre la constitución, la justicia no es dios, aunque si le reconoce (la libertad de religión y de culto es ya un buen punto de partida para ésta cuestión); así como no podemos decir que está ubicada en un orden superior, menos podemos ni siquiera sugerir que está en planos inferiores. Claro que desde el ámbito de la jerarquía la justicia posee cierta superioridad, y lo es respecto del resto de ordenes jurídicos. No por un simple ocurrencia del legislador vino a ser ubicada en la norma de máximo rango, la norma constitucional.

Esta posición de jerarquía que se plasma en la justicia lleva en sus adentros lo que en la teorla general de los valores ha sido presupuestada por el Profesor Garcla Maynez, al representar que los valores desde topicos generales y atendiendo a su visión jurídica poseen una caracterización muy especial, que les permite a nuestro modo de ver situarse en un estalus privilegiado y de muy alto nivel. Esto es así en vista que los valores: a) sirven de fundamento a los fines, con los que tendremos una relación condicionada de los primeros para con los segundos; b) fundamentan el deber de realizar los fines: b.1) por parte de los creadores de las nomas, (las normas no pueden tener cualquier contenido, mucho menos no puede estar determinada simplemente por el cumplimiento de requisitos (ormales); b.2) por parte de los aplicadores (quienes no deben someterse a una aplicación mecánica del derecho al interpretar las normas legales. Desde este punto de vista "la interpretación debe hacerse sin perder el nexo con las otras normas del sistema y sobre todo con los criterios de valoración que sirven de faro a los creadores de las normas 86"; y b.3) por parte de los destinatarios (con lo cual condicionamos la actitudes de obediencia de éstos, y que ellos asumen una actitud valoradora del sistema, diriamos, que aparte de tener en cuenta la validez y positividad del sistema de derecho).

En definitiva, la justicia tiene una posición en el sisterna y siguiendo de nuevo al profesor García Maynez le ubicará dentro de aquellos valores que tienen el carácter fundamental. Y que a su vez siguiendo la escala jerárquica se valdrán de valores consecutivos entendidos como consecuencia inmediala de la realización armónica de los fundamentales: como serían la libertad, la igualdad y la paz social y valores de tipo instrumental, los cuales son entendidos como aquellos que realizan los consecutivos y los fundamentales y que se expresan en todos aquellos derechos de tipo procedimental o adjetivo. No obstante lo anterior, la 
jerarquía de la justicia puede moverse más en razón de otros caracteres de los valores como son la objetividad y la subjetividad en la que no hay formulas absolutas, sino manejables en términos de predominancia de uno u otro carácter.

\subsubsection{Contenido: explícito e implícito.}

En último lugar debe poseer un contenido que le haga distinguible de los otros valores. He aqul la mayor problemática que presenta la justicia en el acercamiento hacia lo práctico. Qué es lo justo para este momento, y qué es lo injusto para hoy. Para no caer en está célebre disyuntiva del contenido de la justicia debe planearse lo que podemos encontrar como puntualizaciones retomadas en la Constitución la mayoría de las veces, y en otras, escondidas en la oscuridad de un concepto que tiene que ser definido o redefinido por medio de la labor interpretativa de la propia Constitución. En otras palabras, existen una serie de elementos que se encuentran expresos y otros que están implícitos. ${ }^{77}$

\subsubsection{Los expresos.}

Los expresos hemos de verlos como manifestaciones directas de la justicia.a) En el poder democrático que apoya y garantiza a los derechos fundamentales y a la división de poderes (órganos según nuestra constitución). Hay ya aquí una clara incidencia en su aspecto formal, desde el punto de vista de lo que reconoce y fundamenta desde adentro del ordenamiento jurídico. El régimen democrático necesita de la justicia como valor.Su necesidad es presupuesto de existencia y de su desarrollo. Retomando los valores superiores reconocidos en la Constitución Española el Tribunal Constitucional del mismo país admitirá de como la justicia es un bastión en el reforzamiento de la legitimidad del Poder. Las instituciones (especialmente cuando regulan conductas) deben respetar los valores superiores en su acción, de ello depende en gran medida su realización verdadera:" Para que la libertad, la justicia, la igualdad, y el pluralismo político, sean una realidad efectiva, y no una enunciación teórica de unos principios ideales; es preciso que a la hora de regular conductas, y por tanto de enjuiciarlas, se respeten aquellos valores superiores, sin los cuales no se puede desanrollar el Régimen democrático que nos hemos dado en la Constitución de 1978"88.

b) Por otra parte la justicia también se manifiesta en los derechos fundamentales que se informan de ella, sean éstos los considerados como los estrictamente individuales, o los aceptados como sociales, económicos y culturales.

c) También la justicia se expresa en el campo de lo organizacional con lo que la acentuación de la justicia está en las políticas del Ejecutivo, en la normación que realiza predominantemente el Legislativo y la interpretación y aplicación que predominantemente realiza el judicial conforme los patrones establecidos por el derecho, sus valores y principios generales. Hemos de ver que este último aspecto, es decir, en el campo judicial encontramos un pleno acercamiento a lo práctico de la justicia, sin menospreciar la labor del Legislativo y Ejecutivo que 
también causan gran labor en las tareas de consolidarla. No obstante, es en el Judicial donde vemos el acercamiento a lo concreto, cuando se resuelven casos específicos en primera instancia o en segunda, y una combinación de lo concreto y general cuando a nivel superior es decir de Corte Suprema se interpreta y se resuelve el caso. Lo que en la visión aristotélica es la justicia Conmutativa, el momento de dar a cada quien lo que le corresponde de acuerdo a la ley. $\mathrm{Y}$ ahora según el estimado axiológico.

d) De otra forma la justicia se expresa en el resto del ordenamiento jurfdico, a través de la serie de principios que podemos encontrar en él y con la normación general en los diversos campos atingentes. En otras palabras la justicia se encuentra ya inmanente en la diversidad de las normas que se promulgan. $Y$ es en éstas que hay ya una expresión de justicia. Lo que sucede es que a veces no le observamos, sino hasta realizar una labor microscópica. En principio es el espiritu concreto de cada norma general. Por ejemplo: Es de juslicia que exista un ordenamiento jurídico que regule al menor infractor, y es también de justicia que en otros campos exista también una normativa que regule la protección del consumidor. Lo que sucede es que la justicia está en la Ley, y se combina con el principio de legalidad informándole. Es en las normas de tipo secundario en donde también se expresa. Y es en donde abarca su tarea desde un plano Jiferente: el secundario. El cual es sin embargo, un principio que debe ser siempre confrontado al valor superior que está plasmado en la Conslitución. Debemos destacar además que el orden valorativo de una ley puede encontrarse en el preámbulo (considerandos) o en la realidad misma que determinó su creación.

Un punto muy importante es que con lodo este razonamiento no podemos llegar a la conclusión que todas las normas son justas. Sin embargo si es de tener en cuenta que a favor de ellas opera la regla de un principio pro-justicia ${ }^{89}$ en su promulgación dimanado del valor justicia reconocido constitucionalmente. En cuestión de legislación, y de promulgación de leyes, la eficacia de este principio es controlado por las garanlías que están ya incluídas en nuestro sistema constitucional. La inaplicación de una norma si el juez la considera inconstitucional y el recurso de inconstitucionalidad en su caso.

\subsubsection{Lo implícito.}

Es de ver que en la tarea judicial constitucional está el mayor margen de la cuestión implícita en la justicia, cuando el juez decide lo que ha de entenderse como justo. Regresamos de nuevo con la apertura del ordenamiento, y la fundamentación de la justicia en el valor y no sólo en las reglas preestablecidas. Por supuesto que para llegar a esta actividad (la de tipo constitucional), no ha de hacerse en forma netamente liberal, es decir sin restricciones, sino coherente con las reglas y valores cstablecidos. Además de que lo implícilo del sistema se muestra especialmente en algunos casos "los diffciles», tratando de consolidar sistemáticamente las demás reglas establecidas y sin menosprecio de la realidad 
circundante. Con ello podemos asumir el art. 421 del Código de Procedimientos Civiles como un mecanismo sentenciador que implica además una preocupación valorativa.

Lo que se quiere poner de maniliesto es que tenemos que tener presente que la neccsidad de dotar de contenido a la justicia que permita la acción y protección de la acción, desde pautas implícitas viene representada básicamente por un contenido que no se quede en la pura formalidad legal, ni menos en el abstraccionismo de la norma jurídica. Ello pone en evidencia los serios inconvenientes prácticos que se enquistan bajo la conceptualización de lo justo. Ya que querer asumir todo bajo el parangón de la ley nos conduce a alejamos de todos aquellos otros elementos 90 , que bien pueden dotar de contenido a la justicia, y que al mismo tiempo dificultosamente es posible ubicarlos totalmente en el orden jurídico, bajo un reconocimiento explícito. De aquí la necesidad del informe de elementos extrajurídicos permisibles por lo jurídico.

En el sentido anterior, la justicia en la Constitución lleva invívito la imparcialidad y no arbitrariedad (no obstante que puedan estar reconocidos expresamente). Con ello retoma el campo de las "decisiones» a nivel de instituciones y que en el campo judicial se expresa en la serie de decisiones que garantizan lo que establece la norma constitucional, en tanto igualdad y libertad de los hombres, y no toma de opciones a favor de uno y otro sin estar debidamente justificada o legitimada la decisión por parte de la norma, seguida de la mecánica interpretativa y lógica del operador jurldico.

En consonancia a la no arbitrariedad es lógico hacer remembranza de la visión Kirchmanniana91 que plagaba en contra sentido a la ciencia jurídica y en especial a la ley positiva con el signo de la arbitrariedad. Posición que malamente puede también en cierto momento hacerse valer para nuestra justicia que está plasmada constitucionalmente. Si la justicia es un valor juridificado, y por tanto es norma positiva, la conclusión efectiva no es más que mostrarla como arbitraria, principalmente si para un sector, la presentan como la pasión que abruptamente penetra bajo la manipulación intencional del legislador y ya no digamos en la del juez. Ante esto hay que suponer necesariamente que para decir si algo es arbitrario tenemos que partir de cuales son las reglas que justifican mencionar que la acción es arbitraria. El profesor Calsamiglia es explícito en este sentido, al concebir la arbitrariedad a partir de un ejemplo. Esta adquiere la connotación propia de su término cuando en el caso de un juego de ajedrez están ausentes las reglas y procedimientos ineludibles para concebir que los participantes están jugando ajedrez. Es así que, si las reglas y procedimientos no se cumplen, o si esas reglas y procedimientos no se dan de antemano, el juego pierde la naturaleza para lo cual fue concebido, es por tanto que la identificación del entretenimiento medieval se dificulta al extremo. Calsamiglia dirá simplemente que el juego ya no lo es92. Es así que la justicia necesariamente conlleva la existencia 
de reglas, y de procedimientos, sin que estos lleguen a la calidad del dogma, y sin que la justicia termine identificándose con los mismos; la justicia y sus reglas en el derecho no son simples ocurrencias, sino producto del esfuerzo del legislador, que debe dejarse auxiliar por técnicos para no incurrir en dirección equivocada, por eso debe ampararse bajo el techo del jurista científico que le permita dar rienda suelta a las actitudes que respetuosamente se manifiesten en pro de lo justo y de los datos y reglas que expresen la justicia en las normas del sistema jurídico. Esto significa admitir una tipología determinada de compostura para no negar «los sentidos correctos» de las normas, y hacer posible que por medio de la conceptualización de la justicia se llenen los posibles vacíos legales, superando las posibles contradicciones e infiriendo o deduciendo las consecuencias sobre las cuales debe asentarse en la práctica la justicia. El Profesor Norberto Bobbio va a rematar con un planteamiento consecuente, señalando que la Jurisprudencia tiene que incluir la rigurosidad del análisis lingüístico que tienen por objeto las proposiciones nomativas de determinado ordenamiento jurídico. Las tareas de los juristas por ende se enmarcan en hacer riguroso el lenguaje legislativo y constitucional, completarlo e incluirlo en el sistema. En el sentido del italiano, el jurista debe respetar la rigurosidad del lenguaje jurídico93, porque, a nuestro modo de ver, ésa es la pauta para no entrar en la arbitrariedad, e indudablemente es por ello que el afán de cumplir las normas y la justicia, debemos estar sujetarnos al método, que ordena y completa para hacer del lenguaje de lo justo algo más riguroso.

Martinez Doral regresa desde una visión iusnaturalista con esa faena que el jurista debe realizar. Lo cual ha de tomarse según nuestra propuesta de igual forma para con la justicia. El jurista debe ocuparse por la interpretación y aplicación de la justicia sin caer en una interpretación y aplicación judaica que se aleje del propio sentido del valor, y debe adquirir el sentido de proponerla dentro de un sistema, para que no adquiera una dispersión e incoherencia, sino una unidad. Por ello Doral enfatiza que el medio para que el jurista realice su labor sistematizadora es el de los conceptos. Así el abogado que "no conoce los preceptos (que es el medio del que disponen los jueces en su actuación diaria) es incompetente94" y todavía más grave el que no conozca los conceptos. "Esa es la gran tarea del jurista como hombre teórico: saber que es una obligación, que es un contrato, en eso radica el saber del derecho", Y también según el agregado nuestro el saber cuando está en presencia de la justicia y de la injusticia en el cambio de los tiempos.

La arbitrariedad por tanto, al igual que la no imparcialidad son el retoque para admitir lo injusto; la no arbitrariedad y la imparcialidad son vetas que deben ser explotadas en la rigurosidad lingürstica para no mellar la justicia. Si se es parcial somos injustos al igual que si pregonamos la arbitrariedad desde las formas $y$ contenidos jurídicos en la constitución. Al respecto de esta tónica es relevante señalar el pronunciamiento jurisprudencial del Tribunal Constitucional Español, 
el cual planta el valor justicia en estrecha conexión con la no arbitrariedad y la discriminación, advirtiendo que admitir la arbitrariedad es menoscabar la justicia, así dirá: "El análisis de un precepto legal desde una perspectiva de «arbitrariedad», se ha de centrar en verificar si tal precepto establece una discriminación, o bien sí, aún no estableciéndola carece de toda explicación racional". En la misma sentencia añadirá que la arbitrariedad incluye la lesión del valor justicia"95

La justicia a su vez siguiendo la tradición aristotélica arribuye una igualdad para los iguales y un tratamiento ponderativamente desigual cuando estamos en presencia de desiguales. En primer lugar, la igualdad es expresión de la justicia aparte de ser un valor fundamental para su consecución. Es igualdad ante la ley, y de un trato igual entre iguales. Pero también implica una tratamiento desigual. Ejemplo de esto está en las políticas gubernamentales y de la asunción de políticas para los más desventajados.

Rawls llevará a nivel macro y específico la noción de justicia. Desde el punto de vista la imparcialidad o la equidad, la justicia muestra las "virtudes" de las instituciones del Estado, y lo que se intenta exhibir no es más, qué principios serían adoptados prefiriendo a las alternativas tradicionales. En las sentencias así, admitimos una fundamentación en el buen sentido (equidad) y razón natural (derecho no escrito). La justicia es imparcialidad, y ésta se expresa en el derecho que tiene toda persona a gozar de un esquema plenamente válido de libertades básicas compatible a su vez con un esquema similar de libertades para todos, primero.Y segundo, en la consistencia del aseguramiento de la igualdad de oportunidades, de tal manera que las desigualdades económicas y sociales existan, pero siempre y cuando se sitúen en el cumplimiento satisfactorio de un doble condicionamiento: así deberán asociarse una igualdad de oportunidades en el sentido de que los cargos y posiciones están abiertos para todos, más la suposición de que impliquen el mayor beneficio para los miembros menos aventajados de la sociedad 9 .

\subsubsection{Nota sobre la movilidad de lo implícito y de lo explícito.}

Como vemos el contenido de la justicia tiene una gran movilidad en sus manifestaciones, tanto en las explícitas como en las implicitas que permitan asf rellenar su contenido. Se tiene una gran movilidad, bastante hay que insistir, en las políticas ejecutivas, legislativas, y judiciales (las normales), y mucho más movilidad en las situaciones extremas(implícitas especialmente) cuando el papel de la Corte toma un rol protagónico. Sin embargo, hemos de ver asimismo donde la justicia se inmoviliza. Admitimos que hay una zona institucional donde la mutabilidad de la justicia se torna nula, « inamovible»: La modificación del territorio, la alternabilidad en el ejercicio de la Presidencia y en la modificación del sistema político. 


\section{La aplicación inmediata del valor justicia en la constitución97.}

Como un penúltimo punto antes de terminar de exponer el tema de la justicia de la constitución es menester detenerse en un punto práctico muy importante. Centramos en lo que sigue el aspecto Judicial.

\subsection{La disyuntiva ley y valor.}

La cuestión Judicial nos lleva a tocar el aspecto de si la justicia puede o no ser aplicada con carácter inmediato por los jueces. En esta perspectiva la justicia obliga al Juez a actuar conforme el patrón normativo que les es característico, es decir, de dejarse seguir, y guiar en su labor interpretativa por el valor superior en la Constitución. El Juez inferior y más el superior están «obligados». El juez en este orden está «vinculado» al igual que el resto de operadores, y con ello se tiende una especie de alfombra que apunta a su vez en la dirección de quienes solicitan justicia. De aqui, éstos también están vinculados por la norma, y por el valor, para que de esta manera sea depositada la confianza en ellos, en los que les asesoran y en los que deciden permitiendo que recaiga la solución de la controversia en uno de los valores fundamentales de nuestra constitución: la justicia. Es según Stammler, el surgimiento de una nueva tarea para llegar a buenos resultados. "este camino consiste en encomendarse a las partes interesadas, a sus consejeros, a los juzgadores para que, en los futuros casos litigiosos, indaguen y descubran por sí mismos cual es en cada caso la solución fundamentalmente justa"98. Podemos afimar que en nuestro derecho los jueces tienen una herramienta para corregir la injusticia de la ley al declarar inaplicable la norma inconstitucional, art. 185 Cnt99.

\subsection{Acercamiento de la justicia a la sentencia Judicial: aplicación inmediata.}

En esta tarea que se encomienda a los jueces se redescubren, con sumo grado, razones que posibilitan la aplicación de la justicia con carácter inmediato. La razón que ha venido siendo incorregible y que hay que corregir es la que se dijo recaía fundamentalmente en la Ley, paso que hay que dejar con la demasía de la aplicación estricta de la inamovilidad del pensamiento legalista. El juez es s6́lo desde aquí aquella «boca muda que pronuncia las palabras de la ley» en la que nada hay que agregar y en la que nada hay que suprimir, en la que nada hay que interpretar, en tanto lo único que existe es aplicación meramente mecánica. Es así que de otra manera podemos llegar a la expresión del principio que venía del liberalismo jurídico en el que las leyes hablan por la boca de los jueces. Dar estos pasos, puede aparentar adentrarse en un abismo de confusiones, especialmente sino se está en condiciones de estableçer el contenido mínimo de la justicia. Sin embargo podemos apreciar una serie de argumentos racionales, que presentamos en los apartados siguientes para determinar su aplicación inmediata. 


\subsubsection{El reconocimiento constitucional.}

La primera razón que puede estimarse es: porque, la justicia está establecida y reconocida jurídicamente. Nuestro constituyente ha dado un paso crucial al dotarle de validez jurídica. Por tanto queda atrás, y muy lejano el principio clásico que había un derecho disociado de la idea de lo justo100. Retomar esta idea disocialiva es caer en una especial concepción de hombre, que por cierto es imposible asumirla, máxime si la postura es verles en siluación angelical. De aquí, la opinión de Bodenheimer al pregonar que " la justicia sin Derecho podría funcionar si gobernantes y jueces fuesen hombres perfectos. Como no lo son, sus poderes para decidir acerca del destino de sus congéneres deben estar sujetos a limitaciones legales"101. Es entonces que el derecho, digarnos correctamente nuestro ordenamiento jurídico se guía por las pautas del valor justicia, la cual no debe verse «ilimitadamente no limitada o ilimitadamente limitada» por la subjetividad judicial y el normativismo legalista. El art.1, ya lo dijo expresamente al asumir jurídicamente que el Estado está organizado para su consecución. Con lo cual el tribunal y con lo que el Juez forman parte de dicha organización y por tanto están obligados a respetarla, a reconocerla y a interpretar las normas con asiento en la justicia. En consonancia a lo anterior, el art. 235 de la Constitución, es todavía más fuerte si no se cree en una posible vinculación jurídica de lo justo para con el juez; en este sentido, al señalar dentro del título VIII la responsabilidad de los funcionarios públicos, establece que: "lodo funcionario civil o militar antes de tomar posesión de su cargo, protestará bajo su palabra de honor ser fiel a la República, cumplir y hacer cumplir la Constitución, ateniéndose a su texto cualesquiera que fueran las leyes, decretos, órdenes o resoluciones que la contraríen, prometiendo además el exacto cumplimiento de los deberes que el cargo le imponga, por cuya infracción será responsable conforme a las leyes". Con esto el juez promete en primer lugar la fidelidad a la Constitución al resolver entre otras cosas los casos que ante él se presentan; por tanto, la justicia en la constitución si la conectamos con el art. $1 \mathrm{Cnt}$ y luego con el art. $235 \mathrm{Cnt}$. da una pauta más sólida para admitir la obligatoriedad de la vinculación judicial para resolver con sede en la justicia sus sentencias.

Con lo anterior se podría argumentar que conseguir la justicia según el art. 1, no es una acción jurídica obligatoria. Creemos que sería erróneo manifestarse en diferente orden. Buscar la justicia es una conducta obligatoria con lo que se revela a la justicia como de aplicación inmediata. Si lo reconoce, está obligado. La acción lejos de estar prohibida, y ser una acción facultativa o libre (que pucda hacerce o no hacerse) es obligatoria.

La obligatoriedad de una acción viene siendo escrita por Atienza, él mencionará que: "Desde un punto de vista muy general, una acción es obligatoria sino está prohibida, ni es tampoco facultativa o libre (puede hacerce o no hacerse). Decir que una determinada acción es obligatoria... implica tanto como afirmar 
que esta permitido realizarla y que no esı́a permitido dejar de realizarla. Cuando esa obligación deriva de normas jurídicas, entonces nos encontramos con una obligación jurídica: por ejemplo, tenemos la obligación jurfdica de pagar los impuestos exigidos por las leyes tributarias, pero no tenemos la obligación jurfdica de saludar'a los desconocidos (que serfa sólo un deber de cortesia)... Es importante tener en cuenta que esta forma de definir la obligación jurídica evita los problemas con que tropiezan los autores que pretenden ligar necesariamente la noción de obligación con la de sanción: decir que una acción $\mathrm{X}$ es obligatoria jurídicamente implicaría tanto como afirmar que si no ocurre $X$ entonces es probable que suceda (como dirfa Benthan) o debe suceder (como dirfa Kelsen; "debe» tiene aquí un carácter normativo, esto es no quiere decir que de hecho suceda) una sanción. La mayor dificultad de estas últimas posiciones es que no pueden explicar diversos supuestos en que se habla de obligaciones jurfdicas que, sin embargo, no llevan aparejadas sanciones". 102 Coadyuvando en la exposición el profesor Atienza vuelve a repetir que cuando la omisión de una acción permitida no está permitida, la acción en cuestión es obligatoria103.

Por otra parte podría también estimarse que el art.1 inc. 1. no mencionó una modalidad del deber ser. Lo cual elimina la obligación, en tanto esta tiene que expresarse con la modalidad deóntica. Con ello llegamos a que en la norma del art 1 inc 1 al no establecer expresamente un deber ser (lo que si se realiza en inc 2 ... "En consecuencia, es obligación del Estado...) no tendría porque suponer una obligación. En realidad esta razón sería inconsecuente al no determinar la aceptación de una obligación. El instinto y el raciocinio lógico jurídico en realidad indica lo contrario, puesto lo que encontramos en el inc. 1 es en realidad un "mandato de suma especialidad deóntica», que no se expresa "llanamente" con un deber ser, sino con un "está organizado para la consecución" de la justicia. Lo que en definitiva viene a establecer la obligación jurídica con una diferente forma al expresar el deber ser. Y por tanto el valor justicia al mismo tiempo de ser una valor superior del ordenamiento jurídico Salvadoreño, reconocido por el ordenamiento constitucional supone la generación de un deber que concatena una obligación superior. 104

Relomando una argumentación consecuencialista, tendríamos que admitir que si la justicia no es obligación nos encontraríamos con una norma sin sentido, o con aquel tipo de normas fantasmas en el ordenamiento jurídico. Interpretación que placenteramente sirve de excusa y de escondrijo para aquellos favoritistas de lo programático. La justicia no está sujela al programa; al contrario el programa está sujeto a la justicia. Así, ésta tiende a realizarlo con los medios que a la época se cuenten. Y en el caso del Judicial, por el hecho de haber una normación menos explícita y poco desarrollada, no puede hacer caso omiso a esa obligación implícita en el primer inciso del art 1. 


\subsubsection{El ordenamiento jurídico vigente continua vigente en su generalidad.}

En segundo lugar, puede añadirse el argumento que destruimos toda la obligatoriedad de las normas y las sujetamos a una especie de justicia que se moviliza según el tenor que la ejecuta. Lo mejor por tanto es mostrar una justicia de grado. Hemos dicho que la justicia está explícita, en el apartado anterior hemos visto los caracteres directos que ello implica. Si el intérprete aplica lo explf́cito de la justicia, la está aplicando inmediatamente. Con ello no destruimos el sistema, el sistema tiene permanencia Y segundo, la justicia tiene un contenido implícito que es el que se dota de suma apertura especialmente en todos aquellos casos especialísimos o diffciles que el juez habrá de resolver. Es en esta labor en donde observamos esa cualidad que por lo general no la habremos de captar a través de un simple sentido visual-literal, sino interpretativo, con lo que la labor de escudriñar microscópicamente para descubrir esa interacción, ese acoplamiento, esa bipolaridad, intensidad y aplicación jerárquica habrá de resaltar y realizarse, logrando de esta manera aparte de la permanencia una movilidad del sistema jurídico acorde a la realidad.

\subsubsection{Necesidad de justicia en la sentencia.}

En tercer lugar, más de alguna opinión podráa añadir que la función de la justicia es simplemente criticar al sistema. La sentencia del Juez no está vinculada en modo alguno, ni debe fallar conforme la justicia, pero si puede ser criticada de legítima o ilegítima de acuerdo el patrón de lo justo. Es lo que solemos escuchar bajo aquella frase " La ley es La Ley". Creemos que la justicia vuelve a repetir su función repatriando la idea de ocupar siempre como primera y última razón el dogmatismo legal. El mecanismo sugerente ya estaba en Stammler al añadir que "lo primero que se pregunta cualquiera que razone jurídicamente es si su querer y su hacer concuerdan o no con el articulado concreto de las normas vigentes; Entonces el juez indaga los artículos del Código, los preceptos de una ley especial, tal vez las normas cristalizadas y técnicamente plasmadas por el Derecho Consuetudinario... El resultado a que puede llegarse por este camino no es nunca la meta final ni absoluta de las consideraciones que en esta materia cabe hacer y que se abren paso siempre. De suyo se comprende que lo que responde a las normas concretas de un orden jurídico positivo puede, a pesar de ello, examinarse críticamente para ver sí además es legítimo en el plano de los principios. Es necesario que el resultado de las consideraciones jurídicas sea además Jus10"105. Y si es injusto habría que agregar, se corregiría, al igual que la injusticia de la ley, mediante la interpretación constitucional realizada por el juez.

\subsection{Acerca del mecanismo protector: el amparo.}

En nuestro derecho operan diferentes principios en materia de amparo. Por ejemplo uno de ellos en el que se guarda una especial relevancia es el de definitividad. Y por medio del cual primero deben de agotarse los procedimien- 
tos y las instancias normales en que el derecho puede ser garantizado, de lo contrario la Sala de lo Constitucional de la Corte puede prevenir al demandante que compruebe haber agotado ésas instancias o que efectivamente las agote en el caso de que de la sola vista de la demanda se pueda deducir que el impetrante no las ha agotado. Un principio que se traduce a la tipologia de una justicia procedimentalista de alto nivel, para acusar una finitud de casos que se deben conocer por medio de una Sala Constitucional de la Corte Suprema de Justicia.

La situación es que en el proceso de amparo procedimentalmente hablando encontramos una serie de principios 106 que operan para generar la protección objeto de la demanda. Con todo ello resulta atractivo discutir si el valor justicia en los términos del art.1 inciso 1_ Cnt, opera al menos como un valor en el juicio. Indudablemente la respuesta que podemos encontrar es que la justicia como valor opera obligatoriamente para los jueces, y que por tanto sus sentencias están vinculadas por el valor justicia en el marco de sus operaciones jurfdicas. El problema y la solución ya se discutfa en el apartado anterior. La justicia está reconocida en la Constitución y los jueces deben atenerse al texto constitucional ( concepto que lo hemos discutido básicamente en dos perspectivas en el apartado 2. la formalidad y la materialidad de una constitución). Ahora bien, la justicia opera como valor y puede hacerlo en el contexto de los procedimientos de amparo, el funcionario público en definitiva está obligado. Sin embargo el amparo nos presenta otra contrapartida y es la de si a la vez quien solicila prolección, puede incoar el valor justicia en su pretensión, accionando en consecuencia bajo el fundamento de tener un valor que a la vez es un derecho que ha ingresado en su patrimonio jurídico. La pregunta es básica i es o no la justicia como valor un derecho objeto de amparo?. El tema propone ya de si un aspecto práctico muy importante, ya que puede mostrar cierta debilidad de la justicia en la Constitución, una vez que está pueda ser conocida por la Justicia Constitucional y sujeta de una desprotección en la esfera judicial. Las respuestas pueden ser duales, y excluyentes. La base de las posibles propuestas redundan en considerar que si la justicia del art.l. es un derecho constitucional o si no lo es. El inclinarse por una u otra dependerá de complementar con otro supuesto básico del cual parte el amparo como juicio constitucional, y es el de que este sólo procede en casos de violación de «derechos consagrados por la constitución» art. 247. Cnt 107. Así el considerar a la justicia como valor y derecho no estaría indicando que puede ser conocida en amparo. Si sólo es valor, el amparo rechazaría dicha pretensión en base a que ha sido construido básicamente para derechos constitucionales.

Desde una visión, que es un primer acercamiento al terna, tenemos que la justicia plasmada en los términos del art.1. inc.1- Cnt. no es un derecho, y si lo fuera, menos podría justificarse como "derecho subjetivo" que pueda ser exigido por el agraviado, sino que tal y como lo establece el art 1. de nuestra Constitución es un valor al cual debe aspirar la actividad del Estado. En la misma exposi- 
ción de motivos de nuestra Constitución se da ése énfasis en respuesta a un «orden axiológico» del Estado Salvadoreño que esta organizado para la consecución de la Justicia. Es un valor que resulta en consecuencia del valor Dignidad Humana que posibilita que se articule que El Salvador reconozca a la persona humana como el origen y fin de la actividad del Estado. Hasta aquí hay que tener presente, que la justicia de la que hablamos es la de pretender accionarla directa y aisladamente de cualquier otro precepto en el juicio de amparo. Lo que conlleva que situarla en una demanda aisladamente como derecho volvería casi imposible su sustentación en una pretensión de parte del agraviado. Sin embargo esto en definitiva no puede implicar que en circunstancias de otro tipo pueda tener aceptación. La posición es que si se ha venido sosteniendo que la justicia es un valor y que va indisolublemente unida a los derechos humanos, tendríamos que admitir que aquellos derechos humanos constitucionales llevan impreso una unión con la justicia y por lo tanto sería imposible no admitir que la justicia a pesar de no ser un derecho humano constitucional, o derecho simplemente constitucional, no tenga por qué no ser admitida como pretensión en una demanda de amparo. De allí podemos concluir que la justicia es objeto de amparo cuando se conecta indisolublemente unida a los derechos constitucionales supuestamente violados ${ }^{108 .}$

Si lo que antecede no resulta convincente, para no considerar a la justicia como derecho constitucional, pero si como una aceptación si se engarza con derechos constitucionales, acudamos entonces a los expositores derecho que puedan auxiliarnos para seguir tomado partido por la tesis anterior. En este sentido es interesante acudir a la idea de los derechos fundamentales y deberes fundamentales que no guardan datos implicativos en sentido correlativo. Un derecho fundamental no implica la existencia de un deber fundamental «siempre», y un «deber fundamental» no conlleva "siempre" la existencia de derechos fundamentales. "El enunciado de la voz derechos y deberes fundamentales exige una serie de precisiones para el en foque correcto del tema: a) no se trata de conceptos correlativos. Cuando alguien tiene un derecho fundamental no siempre existe una relación correlativa de un deber fundamental, respecto del que se pueda entender que tiene un deber fundamental que corresponde con ese derecho. b) Tampoco se trata de conceptos opuestos. La carencia de un derecho fundamental no supone la existencia de un deber fundamental, ni tampoco la inexistencia de un deber fundamental supone la existencia de un derecho lundamental." $109 \mathrm{La}$ visión anterior será confirmada por Alexy desde un plano más gencral, al referirse al carácter relacional de los derechos desde una visión Iríadica, que para cfectos sustentatorios enfatizamos en la relación diádica que Alexy incluye en su fenómeno trialista. En concreto, Alexy al ilustrar los derechos subjetivos y al inclinarse en sus explicaciones por las posiciones de las obligaciones en el círculo de las relaciones jurídicas declara de como esquemáticamente podemos hallarnos en presencia de una obligación relacional y de una no relacional. Siendo 
la relacional la que indica que cuando «a» tiene un derecho frente a «b», este está obligado frente a «a». y la no relacional cuando «b» está obligado frente a «a», lo cual puede significar que "nadie o que algún tercero tenga derecho frente a ello" (a la obligación de b). 110

Si extendemos esta concepción a los derechos constitucionales protegibles por medio del amparo en nuestro ambiente jurídico, podemos llegar al mismo resultado. No hay una relación que asuma la vieja y «antiquísima teoría de los correlativos", por tanto puede haber derechos constitucionales, sin implicar deberes constitucionales, y deberes constitucionales que no signifiquen en el extremo de la relación jurídica constitucional derechos constitucionales. Este supuesto es el que se presenta en el caso de amparo. La justicia, como valor, enfocada en la perspectiva del art.l. inc.I_Cnt. no representa en definitiva un derecho constitucional del ciudadano, más si un deber constitucional y superior del Estado. Pero que no sea un derecho especialmente subjetivo, no quiere decir que al ser propuesta en una pretensión por el agraviado, junto a los derechos constitucionales que considera violados, no pueda ser objeto de admisión en una demanda de amparo. La razón es obvia, y es la de ser una fundamentación positivada, y un valor reconocido que indisolublemente está unido a los derechos constitucionales que puedan caber en el ámbito de una pretendida protección vía el juicio constilucional que discutimos.

Otra pauta que puede ayudar ha seguir sosteniendo el accionar de la justicia como valor junto a los derechos constitucionales es su conexión con la no arbitrariedad. Recordemos que hemos conectado la justicia con la no arbitrariedad, lo cual implica que al estar en presencia de la arbitrariedad, estamos trazando un contorno que lesiona lo justo. Por lo que si hay arbitrariedad, hay injusticia, y si se quiere rehabilitar ésta, es posible accionarla como valor en el amparo, pero siempre que se conecte con un derecho constitucional. Esta pauta que exponemos puede denotarse en el amparo N-1-D-82. Sentencia 1986 y amparo N_14-G-89. improcedencia 1990, en los que se expresa que "para que una persona tenga derecho a ser protegida por el amparo constitucional es necesario que haya sido violado arbitrariamente uno de sus derechos"III

La razón que resta y complementa la argumentación es la de que como ya se ha sostenido, porque, la justicia es de aplicación inmediata, y un valor que atrae consigo una obligación jurídica superior para los órganos e instituciones Publicas encargadas de hacerla realidad.

\section{La justicia es absoluta o es relativa en la Constitución.}

Creemos que a las alturas del presente trabajo asaltará al lector una interrogante crucial. Y es la de si la justicia en la Constitución es absoluta. O si por el contrario es relativa. Algunos pistas a lo largo de la exposición pueden resultar evidentes. No obstante nos detendremos un instante en esta doble vertiente para que no se 
confunda la perspectiva pretendida. Esto puede aparentar que es un toma de una posición casimediana. Y en realidad lo es, por cuanto pretendemos un acercamiento más que a la absolutez de lo justo un acercamiento a su relatividad «con el adicional carácter de tener una tendencia hacia la universalización». Para respaldar el rechazo, hemos de presenciar que se dan razones fundamentales de la tendencia universalizante de la justicia persiguiendo el tipo de la relatividad: porque, no depende del monarca, no depende del dictamen unipersonal. No hay razón tomar el criterio de que es justicia una sola persona. Lo absoluto por lo general cierra con el sujeto que detenta y dice que es. No hace falta añadir que estamos en la época de los Estados contemporáneos y que el poder, ha dejado de ser un tipo de poder asentado en la unipersonalidad decisoria del gobernante. En este momento estamos en presencia de toma de decisiones que en «teoría» debe estar asentadas en los canones del Estado de Derecho, agreguémosle social y democrático, en donde la base del pluralismo político juega un bastión importante. Por ello en resumidas cuentas la justicia se ubica desde el presupuesto democrático. Y el principio de la democracia es claramente un juego de mayorías que respetan a las minorías, es una integración multifactorial.

Una segunda razón para dirimir el conflicto entre lo relativo u lo absoluto en lo justo es el factor tiempo y el territorio. La justicia no es válida para todo época, y en cualquier espacio geográfico. Cada país tiene su propia concepción, cada nación o digamos correctamente cada Estado, asume la justicia en orden a su tiempo que vive y en orden al espacio en donde tiene su asentamiento. No es lo mismo retomar el parámetro de justicia desde una visión de los países occidentales que el hacerlo desde los orientales. $Y$ asf mismo no es lo mismo retomar la justicia a través del tiempo que desde las propias tradiciones vistas intemporalmente.

Y una tercera razón tendría que añadirse, es que la justicia en la Constitución en cuanto interactúa con otros valores no la convierte en un valor absoluto.

\section{Conclusiones:}

6.1. La justicia tiene una constancia «formalista» a través de los tiempos, en la tradición occidental desde los griegos venía plasmándose en la argumentación para conseguir, el equilibrio, la armonía, y el orden en la universalidad reducida de los ciudadanos, asentada sobre una organización sumamente diferenciadora de los libres y los esclavos. El valor de los griegos construye así una tipo de justicia que viene siendo abordada desde una materialidad cósmica, inmersa a la vez, en una conjugación "politeosofica», coadyuvada más tarde por la formación de un ciudad-estado caracterizada en sus escritos por una fisonomía participativa para con los ciudadanos. En estas circunstancias se asoma toda una evolución histórica de la justicia que se ha presentado sintéticamente a lo largo de toda esta exposición; en la cual se incluyen filossofos del calibre de Anaximandro de Mileto, Pámenides 
de Elea, Heráclito de Efeso, Pilágoras, Homero, Hesíodo, Esquilo, Sófocles, Herodoto de Halicarnaso, Trasímaco, Caliclés, Protágoras de Abderas, Sócrates, Platón y Aristóteles, Antístenes, Diógenes y Epicuro. Incluídos en el período más influyente que trazó el diagrama que se acomodará posteriomente en el derecho elaborado por la capacidad romana y el intermedio histórico medieval; en los cuales veremos a Cicerón y Ulpiano en la tradición romana y San Agustín y Santo Tomas en la medieval. Luego la justicia será construida desde el Estado elaborado por los modernos, para que después sea incluida en las sucesivas transformaciones de éste hacia lo social y lo democrático. En estos sucesivos cambios de organización social, ahora convertida en Estado volvemos a encontrar a grandes pensadores: en Hobbes, que asienta la absolutez de lo positivo, en Locke el liberalismo iusnatural, Rousseau el liberalismo desde la soberanla de la voluntad general, Kant con su imperativo categorico, Marx pregonando el igualitarismo, Nozick el anarquismo y Rawls desde un eclecticismo que prioriza la libertad.

6.2. La Justicia ha tenido una notas muy importantes en la historia se dijo. Pero cuando de protegerla y hacerla práctica se trata hay que entroncarla con la admisión de su validez desde la concreción jurídica constitucional. Así la justicia es reconocida en nuestra Constitución, el cual es ya el primer paso para hacerla realidad. Con lo cual se le brinda el aseguramiento de manifestarse en los diferentes ordenes y campos constitucionales, y sistemas secundarios. Desde aquí la justicia asume un contenido axiológico o valorativo que sustenta a la persona humana y su dignidad como el origen y el fin de la actividad del Estado.

6.3. La justicia por tanto es un valor jurídicamente constitucionalizado y se impregna de caracteres generales de los valores superiores en un sistema jurfdico. En tal sentido, le encontramos encarnada en el objeto jurfdico por excelencia: la Constitución. Desde la cual asume una interacción con otros valores: la seguridad, el bien común y la dignidad humana; e introyecta además un solución de continuidad jurídica con los derechos humanos reconocidos (en sentido amplio) y derechos constitucionales plasmados jurídicamente. La justicia subraya dentro y fuera de sí una bipolaridad, que como método colabora para mediar en la solución casuística de las controversias, al poder advertir intuitiva y emocionalmente una primera respuesta, que deberá ser rechazada o aceptada conforme las demás reglas establecidas en la normatividad jurídica. La justicia advierte también una utilización variable, de acuerdo al grado más y menos intenso con que deba de emplearse, conciliando, el bien común y la seguridad, la - libertad y la igualdad. La justicia sostiene en adición una posición en el sistema; que le dota de una jerarquía relativa, ya que a la vez comparte posición con la seguridad y el bien común. La justicia a su vez comporta un contenido explícito e implícito en el sistema. Lo que conlleva en la mayoría de las veces a una casi identificación con la constitucionalidad en primer lugar y la legalidad de segundo grado. En términos implícitos comporta actuación judicial esencialmente, y he aquí la tarea de los jueces que pueden tener la virtud de inaplicar las normas 
cuando contraríen la constitución o en alto nivel interpretarla en consonancia con las reglas del sistema y con una posible apertura racional, ponderada, no arbitraria, ni discriminativa que sucedáneamente la justicia en la constitución pueda permitir. Por supuesto que la justicia en lo explícito no se reduce a la ley, no es la ley ni es la constitución, como tampoco es reducción a la legalidad; pero si informa a la constitución desde la interioridad jurídica que le brinda el reconocimiento constitucional, y al resto de principios consagrados en los diferentes subsistemas jurídicos, entre los cuales el principio de legalidad no puede quedar inmune. Por supuesto también, hay que admitir, que la justicia no se expresa solamente en la actuación judicial, sino de igual manera en el ámbito de las instituciones, desde aquf podemos incoar la justicia como la directriz de la planeación expresa por mandato constitucional y podemos denotarla como la planeación implícita por las aperturas que el mismo sistema jurídico pueda dotarles para el ejercicio de sus labores.

6.4. La justicia en el campo judicial representa un valor de suma importancia. Para el juez representa un valor que tiene que aplicar en forma inmediata, por la obligación constitucional que la justicia representa desde el art.1. inc 1. ya no digamos por la expresividad con que la misma se muestra en el inc.2. Hay que advertir que el juez aplicando justicia, no es juez destructor del sistema jurídico válidamente promulgado. Siempre tiene que atenerse a los datos, a las reglas del sistema, como razones "prima facie» ya que en sí mismas opera el principio pro-justicia a favor de ellas. El que no lo sean dependerá de una posible inaplicación y de otros controles normativos que el orden jurídico, especialmente en el constitucional han sido diseñados para tal efecto.

6.5. En la justicia encontramos un caso singular, en relación al amparo, en el cual puede operar con razón inmediata y relativamente directa siempre y cuando se arguya como razón explicativa la indisolubilidad con los derechos constitucionales que el supuestamente agraviado, pretende proteger.

6.6. Acerca de su relativización o absolutización tenemos, que no es en términos totales relativa ni absoluta. Mas bien tiende a una universalización. La unión jurídica de los Estados en el contexto mundial así lo demuestra. La ratificación y firmas de tralados internacionales pone en claro que la misma se adentra en un mundo que acerca cada vez más para asumir normas y valores que rescaten la universalidad pretendida en otros tiempos. «La universalización tendente» de la justicia es entonces ya una muestra de una no relativización absoluta, ni de una absolutización de la misma.

6.7. No hay que confundir la justicia constitucional, administrada por los jueces, en especial por los de máximo rango; con la justicia en la Constitución que obliga a la justicia Constitucional, y a otros tipos de justicia desarrollada ejecutivamente o bien legislativamente, y no porque esté encima del orden jurídico, sino por su propio reconocimiento en la norma Constitucional. 
6.8. La justicia en la Constitución desde lo justo, es el toque más acertado que ha hecho el constituyente en la Constitución de 1983. Normativamente la justicia en la Constitución, como no ausencia de reglas, la inaceptabilidad de la arbitrariedad o parcialidad, la regulación y distribución de poderes (órganos) dirime el conflicto entre una justicia justa e injusta en nuestra Constitución suponiendo para el aplicador e intérprete una justicia justa a ser aplicada en interpretada en la «realidad jurídica constitucional». No obstante, el acercamiento de la realidad normativa constitucional, con la realidad social del medio salvadoreño, podría dejar entrever una brecha muy amplia para su eficacia certera. En especial cuando desde las estructuras, que visualmente podemos encontrar, no parece mostrarse un fortalecimiento de la mayorías populares y «débiles» en el reconocimiento judicial de sus derechos o de las ventajas a las que tienen derecho los menos favorecidos. El desajuste fiscal para nuevas inversiones educativas, y planes sociales, parecen mostrarlo, el abarrotamiento de la demanda del público en los tribunales parece ya ser un problema irresoluble, a parte de la poca eficacia para con aquellos grupos que funcionan al margen de lo legal y de una justicia constitucional y sin menosprecio de los golpes que los encargados de la seguridad pública hayan infringido a «bandas poderosas y organizadas».

\section{Bibliografía:}

Asimov, Isaac : Los Griegos una gran aventura. Traducción de Néstor Míguez. Alianza editorial. Madrid 1990. 1a. reimpresión. Título original: The Greeks: A Great Adventure. Publicado por acuerdo con Houghton Miflin, C. Boston, Mass,USA, 1965.

Atienza, Manuel : Tras la justicia. Una Introducción al Dereche y al Razonamiento Jurídico. Ariel-Barcelona 1993. 1a. Edición.

Alexy, Robert: Teoría de los Derechos Fundamentales. Traducción de Ernesto

Garzón Valdés. Centro de Estudios Constitucionales. Madrid 1993. 1a. Edición. Tftulo original: Theorie Der Grundrechte. Suhrkamp- Verlag. 1986.

Bertrand Galindo, Francisco y otros autores: Manual de Derecho Constitucional. Centro de Investigación y Capacitación, Proyecto de Reforma Judicial, San Salvador, El Salvador. 1992.1a. Edición.

Bobbio, Norberto : Igualdad y Libertad. Traducido por Pedro Aragón Rincón. Editorial Paidos 1993. 1a Edición. Título original: "Equaglianza" y "liberta". Artículos publicados en Enciclopedia del Novecento Vol ll.

Bobbio, Norberto: Conuribución a la Teorfa del Derecho. Editorial Debate-Madrid 1990. la. Edición.

Bobbio, Norberto: Teoría General del Derecho. Editorial Debate-Madrid 1992. 1a. Edición.

Bodenheimer, Edgar: Teoría del Derecho. Fondo de Cultura Económica. Traducido por Vicente Herrero. México 1994. 14a. Reimpresión. Título original: 
Jurisprudence. 1940. Mc Graw-Hill Book Company Inc. New York.

Calsamiglia, Albert: "Sobre la Ciencia Jurídica". Anuario de Derechos Humanos, número 4. Madrid-Facultad de Derecho de la Universidad Complutense. 1986-1987.

Copleston, Frederick : Historia de la Filosofía. Vol. I de Grecia y Roma. Traducción de Juan Manuel García de la Mora. Editorial Ariel-Barcelona 1986. 2a. edicion. Título original: A History of Philosophy. Vol.I Greece and Rome. Burns and Oates Itd- The Bellarmine series IX.

Clavero, Bartolomé: * Garantie Des Droits». Emplazamiento histórico del enunciado Constitucional. En Revista de Estudios Políticos. Nueva época número 81, julio-septiembre 1993. Centro de Estudios Constitucionales. Madrid.

De Asis Roig, Rafael: Deberes y obligaciones en la Constitución. Centro de Estudios Constitucionales-Madrid 1991. 1a. Edición.

Dworkin, Ronald : El imperio de la justicia De la teoría General del Derecho, de las decisiones e interpretaciones de los jueces y de la integridad política y legal como clave de la teoría y práctica. Traducción de Claudia Ferrari. Gedisa 1988.1a. Edición. Tílulo original: Law's Empire. By Harvard University, Press, Cambridge, Mass 1986.

Errazuriz Mackenna, Carlos Jose : La Teoría Pura del Derecho de Hans Kelsen. Universidad de Navarra, S.A. Pamplona, 1986. 1a. Edición.

Fernández, Eusebio: Estudios Sobre Etica Juridica. Debate Madrid. 1990. 1a. Edición.

Fernández, Eusebio: Teoría de la Justicia y Derechos Humanos. Debate-Madrid 1984. la. Edición.

García Canales, M.: "Principios Generales y Principios Constitucionales". En Revista de Estudios Políticos. Nueva época número 64, abril-junio 1989. Centro de Estudios Constitucionales. Madrid.

Gracia, Diego : Fundamentos de Bioética. Eudema. Madrid 1989.1a. Edición.

Guerrero Salom, Enrique : "Evolución del pensamiento político" en Introducción a la Ciencia Política. Compilación de Ramón García Cotarelo y Juan Luis Paniagua Soto. Universidad Nacional de Educación a Distancia- Madrid. 1a. reimpresión.1992.

Fernández Galiano, Antonio y otros: Presocráticos, Sofistas, Sócrates, en "Filosoffa del Derecho". Universidad de Educación a Distancia- Madrid.1988.3a. Edición.

Finley, Mosés I.: "La Grecia Antigua, economía y sociedad". Traducción de Teresa Sempere. Editorial Crítica grupo Editorial Grijalvo-Barcelona 1984. 1a. Edición. Título original: Economy and Society in Ancient Geece, publicado por Chatto \& Windus Ltd, Londres.

Frondizi, Rosiere: ¿Qué son los valores?. Brevarios del Fondo de Cultura Económica. México 1994. 12a. Reimpresión.

Geiger, Theodor: Moral y Derecho. Polémica con Uppsala. Editorial Alfa. Traducción de Ernesto Garzón Valdés. Editorial Laia S.A- Barcelona 1982. 
Título Original de la obra Uber Recht Und Moral - Streitgesprach mit Uppsala-

Giammattei Aviless, Jorge Antonio y Criollo, José Emesto: Justicia Constitucional. Publicaciones Especiales de la Corte Suprema de Justicia. Número.15. San Salvador, El Salvador. C.A. Diciembre de 1993.

Goldschmit, Werner: La Ciencia de la Justicia.(Dikelog(a). Ediciones Depalma. Buenos Aires 1986. 2a. Edición.

Gutiérrez Castro, Gabriel Mauricio. Derecho Constitucional salvadoreño. Catálogo de Jurisprudencia (segunda edición). Número 7.

Herdeber, Matthías: "La Jurisprudencia Constitucional en el Derecho Comparado". En Revista Contribuciones 2-94 "Estado de Derecho" Fundación Konrad Adenauer. Centro Interdisciplinario de Estudios sobre el Desarrollo Latinoamericano CIEDLA.

Hernández Martínez, María del Pilar :Reflexiones sobre la teoría de la Constitución y del Derecho Constitucional. Boletín Mexicano de Derecho Comparado, Nueva Serie, año XXV No 73. enero- abril 1992. UNAM.

Hoyos, Arturo: El Control Judicial y el Bloque de Constitucionalidad en Panamá. Boletín Mexicano de Derecho Comparado. XXV, número 75, septiembre-diciembre de 1992.

Kirchmann, J.H. VON: La Jurispnudencia no es Ciencia. Madrid- Centro de Estudios Constitucionales 1983. 3a. Edición.

LaTorre, Angel: Introducción al Dereche. Ariel- Barcelona 1990. 6a.Edición.

Lorca Navarrete, J.F.: Justicia-libertad. Fundamentos filosóficos del Derecho.Ediciones Pirámide 1979. Ia. Edición.

Marlasca Martínez, Olga : Elementos Jurídicos y Extrajurídicos en el Derecho. En Revista Estudios Deusto. Universidad de Deusto. Segunda Epoca. Vol. 41/1 Enero-Junio 1993.

Martínez Doral, Jose María: "Sociólogos, Juristas, Filósofos. Apuntes para una metodología del derecho". En Revista Chilena de Derecho, volumen 17. número 3, septiembre-diciembre de 1990. facultad de Derecho Pontificia de la Universidad Católica de Chile.

Martínez García, Jose Ignacio: "Ficciones en la Construcción del Derecho". En Revisia Estudios Deusto. Universidad de Deusto. Bilbao. Vol 37/2, julio-diciembre de 1989.

Nozick, Robert: Anarquía. Estado. Utopía. Fondo de Cultura Económica 1988. Título original: Anarchy, state and utopía. 1974. Basick Books Inc. New York.

Ollero Tassara, Andrés: Derechos Humanos y Metodología Jurídica. Centro de Estudios Constitucionales. Madrid 1989. 1a. Edición.

Pataro, Enrico: "Modelos de razón y tipos de razón Jurídica". En Revista Estudios Deusto. Universidad de Deusto. Bilbao. Vol 37/2- julio-diciembre de 1989.

Peces Barba Martínez, Gregorio: Prólogo a la Constitución Española de 1978. 
En Constitución Española de 1978. Editada por Centro de Estudios ADAMS. Peces Barba, Gregorio: Nota sobre la Justicia en Derecho y Derechos Eundamentales. Centro de Estudios Constitucionales-Madrid 1993.1a Edición.

Peces Barba Martínez, Gregorio: Etica Pública y Derecho. Discurso de recepción de Académico de número en la Real Academia de Ciencias Morales y políticas de Madrid. 1993.

Pineda, Fabio Hercules: Sentencias. Separata de la Revista Judicial. Corte Suprema de Justicia. Número 1. Mayo 1989. San Salvador. El Salvador. C.A. Epoca de septiembre de 1984, 24 de mayo de 1989.

Polin, Raymond: $\boldsymbol{L}$ justicia en la filosofia de Locke. En La Justicia. Compilación de Carl J. Friedrich y John W. Chapman. Editorial Roble- Mexico.1969. Título original: Justice Nomos VI. Por Prentice Hall-Hall, Inc. Atherton Press, New York.1963.

Pokrovski, S.: Historia de las Ideas Políticas. Tratados y manuales GrijalboMéxico 1966. Traducido por Carlos Marín Sánchez. Título Original: Istoria Politicheskij Ucheniy.1a. Edición.

Prieto, Fernando: Historia de las Ideas y de las Formas Políticas. Tomo I. Edad Antigua. Unión Editorial- Madrid 1990. 1a. Edición.

Puy, Francisco: "Principios Generales del Derecho". En Revista Estudios Deusto. Universidad de Deuslo. Bilbao. Vol. 37/2- Julio-Diciembre de 1989.

Ras, Aurelio: Reflexiones sobre la filosofía. Librería Beltrán Madrid.1a. Edición. (Sin año de publicación ni impresión)

Rawls, John: " Las Libertades Fundamentales y su Prioridad". En JOHN RAWLS Y OTROS: Libertad. Iqualdad y Derecho. Ariel-España 1988.1a. Edición. Título original: Liberty, Equality and Law. Select Tanner lectures on Moral Philosophy. 1987. The Press Syndicate of the University of Cambridge.

Recasens Siches, Luis.: Direcciones Conlemporáneas del Pensamiento Jurídico.

(La filosofía del Derecho en el siglo XX). Editora Nacional-México. Universidad de Santiago. la. edición. 1981.

Rickert, Enrique: Ciencia Cultural y Ciencia Natural. Traducido del alemán por Manuel G. Morente. Colección Austral, Espasa Calpe- Argentina.1945. 2a. Edición.

Rodríguez Paniagua, Jose María. "Historia del pensamiento jurídice I. De Heráclito a la Revolución Francesa". Universidad Complutense, Facultad de Derecho, dirección de Publicaciones 1988. 6a. Edición.

Rubio Carracedo, José: Paradigmas de la Política. Del Estado Justo al Estado

Legítimo (Platón, Marx, Rawls, Nozick). Anthropos. Editorial del hombre 1990.1a. Edición.

Ruyer, Raymond:_Filosofía del Valor. Traducción de Agustín Ezcurdia Hijar. Fondo de Cultura Económica México 1974. la. reimpresión. Título Original: Philosophie de la Valeur, en Librairie Armand Colin 103. Boulevard Saint Michel, París. 
Skolimowski, H.: "Las cuatro tradiciones axiologicas del hombre occidental y hacia dónde vamos". Tomo XVIII número 309. En Revista Folia Humanistica. Julio-agosto 1989.

Stammler, Rudolf: El Juez, El pensamiento filosofico Jurídico de Stammler. Editora Nacional. México 1980. 1a. Edición.

Tobeñas, Jose Castan: Los Derechos del Hombre. Reus-Madrid 1985. 3a. Edición.

Touchard, Jean. "Historia de las ideas políticas". Tecnos Madrid 1990, 3a. reimpresión. Título original: Histoire des idées politiques, publicada en Presses Universitaires de France, de París.

Truyol y Serra, Antonio: Las primeras especulaciones en torno a la Justicia en Historia de la Filosofía del Derecho y del Estado.l. De los orígenes a la baja Edad Media. Alianza Universidad textos 1989. 9a. Edición.

Uscatescu, Jorge : Evocación de Carl Schmitt. En Revista Folia Humanística. Tomo XXVIII, número 313, marzo- abril 1990. Barcelona.

Van Dunne, Jan M.: Los Valores Personales en el Razonamiento Jurídico. En Revista Estudios de Deusto. Universidad de Deusto. Bilbao. Segunda Epoca. Vol 38/1. Enero-Junio 1990.

Vanni, Icilio: Filosofía del Derecho. Traducido por Rafael Urbano. Francisco Belırán Editor Librería Española y Extranjera. 1922 la. edición.

Verges Ramírez, Salvador: "Derechos Humanos y Justicia. Evolución de la Justicia y el Progreso de los Derechos Humanos". En Revista Estudios de Deusto. Universidad de Deusto. Bilbao. Segunda Epoca. Vol. 39/2. JulioDiciembre 1991.

Verdu, Pablo Lucas: "Reflexiones en tomo y dentro del concepto de Constitución. La Constitución como norma y como integración política". En Revista de Estudios políticos. Nueva época número 83, enero-marzo 1994. Centro de Estudios Constitucionales. Madrid.

Zorilla Ruiz, Manuel María: Aplicación del Derecho Objetivo por la Justicia Constifucional y la Jurisdicción Ordinaria. En Revista de la Universidad de Deusto. Bilbao. Segunda época. Vol 42/1. Enero-Junio 1994.

Otros:

Enciclopedia Jurídica Ome. Tomo XVII. Jact-Lega. Driskill. S.A. Buenos Aires. 1982.

LEX: Primera Convención Nacional de Abogados. San Salvador. 1957.

Conferencia Nacional sobre Justicia y Sociedad. San Salvador, abril.1995. Corte Suprema de Justicia.

El Mélodo de Historización de los conceptos de Ignacio Ellacuría. En Revista Estudios Centroamericanos ECA. Número 553-554 noviembre-diciembre 1994. 
Pronunciamiento en la Conmemoración del quinto aniversario de los mártires de la UCA, Universidad Centroamericana "José Simeón Cañas". El Salvador necesita realismo y esperanza. En Revista Estudios Centroamericanos ECA. Número 553-554 noviembre-diciembre 1994.

\section{Notas}

1. Cabe advertir que la justicia« siempre» ha estado en la discusión, otra cosa será que para algunos la justicia se vuelve vacía de contenido, o se nos presenta como un concepto inexistente y sin importancia para la tutela del derecho. Es acá sin duda el desborde por el pesimismo acerca de la justicia. La justicia en esta corriente es la "expresión de las preferencias, de los sentimientos o de la voluntad, pero no está dentro del ámbito de lo que racionalmente se puede debatir". (Pág 206 PECES BARBA al explicar las posiciones pesimistas). Con Kelsen por ejemplo, se estigmatiza como fórmula vacía para justificar cualquier orden social. La justicia en nada tiene que ver con el derecho. (Vid. su obra ¿Qué es Justicia?). VID. Gregorio Peces Barba: Nota sobre la Justicia en Dereche y Derechos Fundamentales. Centro de Estudios Constitucionales-Madrid 1993. 1a. Edición. Pág 201 y ss. Puede consultarse también acerca de Kelsen y su relegación de la justicia al campo de la ética como campo de nomas morales separadas del sistema jurídico a Carlos José Errazuriz Mackenna: La Teorla Pura del Derecho de Hans Kelsen. Universidad de Navarra, S.A. Pamplona, 1986. 1a. Edición. Pág 335 y ss.

2. María Marín Castán Tobeñas dirá, que la justicia desde una concepción actual "viene siendo aceptada como un valor con finalidad propia y primaria del derecho y como armonizador de los fines individuales y los fines sociales o comunitarios del derecho, aunque aceptando como criterio básico el del reconocimiento del valor absoluto de la persona". CIT. en José Castan Tobeñas: Los Derechos del Hombre. Reus-Madrid 1985. 3a. Edición. Pág 74.

3. VID.Icilio Vanni: Eilosofía del Derecho. Traducido por Rafael Urbano. Francisco Belırán Editor Librería Española y Extranjera. 1922. 1a. edición. Págs. 238 y ss.

4. CIT. Antonio Truyol y Serra: Las primeras especulaciones en torno a la Justicia en Historia de la Filosofía del Derecho y del Estado.l. De los ongenes a la baja Edad Media. Alianza Universidad textos 1989. 9a. Edición. Pág. 104.

5. VID. Fernando Prieto: Historia de las Ideas y de las Formas Políticas. TOMO I. Edad Antigua. Unión Editorial-Madrid 1990. 1a. Edición. Pág. 58.

6. VID. V.S.Pokrovski: Las teorías políticas en la Antigua Grecia en Historia de las Ideas Polfíticas. Tratados y manuales Grijalbo-México 1966. 
Traducido por Carlos Marín Sánchez. Título Original: Istoria Politicheskij Ucheniy. la. Edición.Pág.48.

7. VID. Antonio Truyol y Serra: Las primeras especulaciones en tomo a la Justicia en Historia de la Filosofía del Derecho y del Estado.l. De los orígenes a la baja Edad Media. Pág. 106.

8. VID. Antonio Fernández Galiano y Otros: Presocróticos, Sofistas, Sócrates, en "Filosofía del Derecho". Universidad de Educación a DistanciaMadrid.1988.3a. Edición. Pág.14 y 15.

9. VID. Enciclopedia Jurídica Omeba. Tomo XVII. Jact-Lega. Driskill. S.A. Buenos Aires. 1982. Pag 652 y ss.

10. VID. Fernando Prieto: Historia de las Ideas y de las Formas Políticas. Tomo I.Pág 59.

11. VID. Fernando Prieto: Historia de las Ideas y de las Formas Políticas, Pág 73.

12. CIT. Fernando Prieto: Historia de las Ideas y de las Fomas Políticas, Pág.71.

13. VID.H. Skolimowski: "Las cuatro tradiciones axiológicas del hombre occidental y hacia dónde vamos". Tomo XVIII, número 309. En Revista Folia Humanistica. Julio-agosto 1989. Pág 272.

14. VID. Edmund Wilson: "Los Rollos del Mar Muerto". Brevarios Fondo de Cultura Económica. México-1994. 3a. Reimpresión. Título original: The Dead sea Scrolls. Oxford University Press, Nueva York. Pág. 44.

15. Véase por ejemplo a Copleston que ordena los períodos de la vida de Platón, entre los cuales destaca el "período socrático", en el cual escribe el libro I de la República sobre la justicia; a pesar de que no será hasta que entre a su "período de la madurez" en el que completará su teoría idealista que plasma en la República acabando así los libros del II al $\mathbf{X}$ sobre el Estado.VID. Frederick Copleston: Historia de la Filosofía. Vol. I de Grecia y Roma. Traducción de Juan Manuel García de la Mora. Editorial Ariel-Barcelona 1986. 2a. edición. Pág.151. Título original: A History of Philosophy. Vol.I Greece and Rome. Burns and Oates Itd- The Bellarmine series IX.

16. Ocupados en casi todas las actividades, salvo las políticas y militares. Aunque éstas dos últimas actividades deben ser consideradas dentro de un margen muy estrecho, en tanto que había predominancia de esclavos en la policía y en los servicios inferiores de la administración. En cuanto a la diferenciación de un esclavo y un hombre libre Finley asegura que no es por la naturaleza de su trabajo que se van a distinguir hombre libre y esclavo, sino por la clase social del hombre que realiza la labor. También añade que los esclavos fueron fundamentalmente extranjeros, al menos después de haber sido abolida la esclavitud por deudas de parte de Solón. Y es así que si en un principio podía esclavizarse a los atenienses por parte de los mismos atenienses, posteriormente les fue vedado, aunque no lo fue 
para con los bárbaros. En síntesis, siguiendo el estilo de aristóteles " la condición de esclavo estará dado por estar coaccionado por otro". Vid. M.I Finley: "La Grecia Antigua economla y sociedad". Traducción de Teresa Sempere. Editorial Crítica grupo Editorial Grijalvo-Barcelona 1984. Ia. Edición. Título original: Economy and Society in Ancient Geece, publicado por Chatto \& Windus Ltd, Londres.Pág 134 y 135.

17. VID. Enrique Guerrero Salom: "Evolución del pensamiento político" en Introducción a la Ciencia Política. Compilación de Ramón García Cotarelo y Juan Luis Paniagua Soto. Universidad Nacional de Educación a Distancia-Madrid. 1a. reimpresión.1992. Pág. 60 y ss.

18. En la vida financiera de Atenas tuvieron un papel prominente. El arrendamiento de granjas, casas y minas les estaba permitido, aunque no podfan comprarlas y hacer préstamos sobre ellas. Fueron excluídos de la propiedad rural-la propiedad de las fincas les estaba negada-, en sus relaciones con el estado no tenían el derecho a pedir que se les ayudara ante la eventualidad de pasar hambre. Finley no recuerda que en el año 445 a.d.C un príncipe africano regaló granos a la ciudad de Atenas y al hacerse la distribución provocó la depuración de la lista de los ciudadanos, porque algunos no ciudadanos habían sido inscritos falsamente como tales. En el campo judicial podian ser llevados a la fuerza ante un magistrado al ser citados en un juicio privado. En otros tópicos podían estar sujetos a esclavitud por ciertos delitos, aunque se les hacía una diferencia ulterior con los libertos. Carecían además del derecho a casarse con una ciudadana, un ejemplo famoso es la Ley de Pericles de 4516450 a de C. que promulgaba dicha prohibición. En materia militar, en caso de pertenecer a un sector acomodado, estaban obligados a ir a la guerra por la fuerza, obligándoseles a servir como hoplitas en la caballería, pagando sus propios equipos. $Y$ en caso de pertenecer al sector pobre podían colaborar en las acciones, normalmente como remeros, aunque tenían la obligación de asistir a la guerra. En caso de hacerlo lo consideraban un honor.VID. M.I. Finley: La Grecia Antipua. Economía y Sociedad. Págs 98, 108, 115, 117, 146 y 166.

19. VID. Enrique Guerrero Salom: "Evolución del Pensamiento Políico" en Introducción a la Ciencia Polltica. Pág 60 y ss. Según Finley, los ciudadanos poseían mayor participación en las reinvidicaciones, privilegios y exenciones. Un ejemplo de ello es el derecho a no pasar hambre, el cual podía en una determinada situación solicitarse al estado; el caso concreto que Finley expone en relación al asunto fue la redistribución de los granos que donó un príncipe africano a Atenas en el año 415 a.de. C. Otros de los privilegios de los que gozaban los ciudadanos era el ir a la guerra, el derecho a formar parte de un jurado, el derecho a participar en la asamblea con igualdad de voto, el derecho a hablar y el de presentar propuestas en la misma. Los ciudadanos estaban sobre los demás hombres, tenían en mate- 
ria de propiedad y contratos una libertad amplia. Asimismo tenían el derecho ilimitado de manumitir esclavos, a pesar que la consecuencia a diferencia de Roma era que los libertos no pasaban a formar parte automáticamente de la ciudadanía. En el campo de los servicios militares, se les aplicaba en similares condiciones que a los no ciudadanos libres: si pertenecían a una clase acomodada estaban obligados a ir a la guerra y a pagarse su equipo, no recibiendo compensación alguna por el costo del mismo. En cambio si eran pobres no tenían la obligación de asistir. En el campo de las relaciones matrimoniales tenían la prohibición de casarse con los no ciudadanos. Y en asuntos de la Hacienda Pública, siempre que fuesen ricos, pagaban un impuesto sobre el capital. Además de asignárseles «la liturgia», que era un impuesto para conseguir recurso por parte del estado, asignándoles la responsabilidad directa de los costos ocasionados para la realización de un festival o bien para la construcción de un trimeme. M. I. Finley: "La Grecia Antigua, Econornía y Sociedad". Págs. 109, 110, $11,115,117$ y 119. Los trirremes fueron un nuevo tipo de barco, que los griegos crearon para protegerse de las invasiones persas, poseran tres filas de remos, "lo cual significaba que podían introducirse más remeros en ése tipo de barco que en los de tipo más antiguo. Eran más veloces y tenían una mayor capacidad de maniobra que los barcos viejos". VID. Isaac Asimov: Los Griegos una gran aventura. Traducción de Néstor Miguez. Alianza editorial. Madrid 1990. 1a. reimpresión. Pág 110 y ss. Título original: The Greeks: A Great Adventure. Publicado por acuerdo con Houghton Miflin, C. Boston, Mass, USA, 1965.

20. En las dos especies de justicia aristotélicas Diego Gracia observará el intento de compaginar lo aristocrático (justicia distributiva), con el sentido popular (justicia conmutativa). VID. Diego Gracia: Fundamentos de Bioética. Euderna. Madrid. 1989.1a. Edición.Pág.218 y 219.

21. VID. V.S. Pokrovski: Las teorías políticas en la Antigua Grecia en Historia de las Ideas Políticas. Pág.70.

22. VID. Fernando Prieto: Historia de las Ideas $x$ de las Formas Políticas. Págs.90 y 91.

23. VID. Fernando Prieto: Historia de las Ideas y de las Formas Políticas. Tomo I. Págs. 157-159.

24. VID. Fernando Prieto: Historia de las Ideas y de las Formas Políticas. Págs. 157-159.

25. CIT. Werner Golchmit: La Ciencia de la Justicia. (Dikelogía). Ediciones Depalma. Buenos Aires 1986. 2a. Edición. Pág.LX.

26. VID. Wemer Goldschmit: La Ciencia de la Justicia. (Dikelogía). Pág. IX.

27. CIT de Fernando O.S.A Campo del Pozo: Filosofía del derecho según San Agustín, pág 27, Archivo Agustiniano, Valladolid 1966.En J.F. LORCA NAVARRETE: Justicia-libertad. Fundamentos filosóficos del Derecho.Ediciones Pirámide 1979. 1a. Edición.Pág. 49. 
28. CIT. J.F. Lorca Navarrete: Juslicia-libertad. Fundamentos filosóficos del Derecho. Pág 50.

29. VID. J.F. Lorca Navarrete: Justicia-libertad. Fundamentos filos 6 ficos del Derecho.Pág 51.

30. Montesquieu es otro autor cotizado de la época de transición. Con el cual es inútil dejar de lado la grandiosa división de poderes que marcó otro hito en las teorías estatales. Sin embargo, la cortedad y premura de estas líneas, solamente nos posibilitan hacer una simple mención.

31. VID. Diego Gracia: Fundamentos de Bioética. Pág. 218 y 219.

32. CIT. Dicgo Gracia: Fundamenlos de Bioética. Pág.220. Vid también, págs 219 y 221.

33. CIT. Diego Gracia: Eundamenlos de Bioélica. Pág.225. Vid también Págs 222 al 224; VID. Raymond Polin: La justicia en la filosofia de Locke. En La Juslicia. Compilación de Carl J. Friedrich y John W. Chapman. Editorial Roble- México.1969. Pág.309 y ss. Título original: Justice Nomos VI. Por Prentice Hall-Hall,Inc. Atherton Press, New York.1963.

34. CIT. Diego Gracia: Fundamenlos de Bioélica. Pág. 227. Vid también: Págs 225 y 226.

35. CIT. J.F. Lorca Navarrete: Juslicia-libertad. Fundamentos filosóficos del Derecho. Pág 37.

36. VID. Robert Nozick: Anarquía. Estado, Utopía, Fondo de Cultura Económica 1988. Título original: Anarchy, state and utopia.1974. Basick Books Inc. New York.Págs 149 y 319.VId también, José Rubio Carracedo: Paradigmas de la Política. Del Estado Justo al Eslado Legítimo (Platón. Marx, Rawls, Nozick). Anthropos. Editorial del hombre 1990.la. Edición. Págs 243 y ss.

37. CIT. Diego Gracia: Fundamentos de Bioética. Eudema. Madrid 1989.1a. Edición.Pág.228.

38. CIT. Diego Gracia: Fundamenlos de Bioélica. Pág. 239.

39. Esta es la interpretación de Diego Gracia.Sin embargo, la mayoría de autores, le verán dentro del marco del nuevo liberalismo. La reestructuración contemporánea de las tesis liberales vuelcan su pauta con Rawls, dirán estos últimos. Especialmente con la justificación limitada de los derechos económicos, sociales y culturales impreso en su segundo principio de justicia como equidad.

40. CIT. Jhon Rawls: A Theory of Juslice, Cambridge, MAs. The Belknap Press of Harvard University Press, 1971; (trad. esp) Madrid. Fondo de Cultura Económica, 1979. Págs. 82. En Diego Gracia: Eundamentos de Bioélica. Euderna. Madrid 1989.1a. Edición. Pág.251.

41. CIT. Jhon Rawls: A Theory of Justice. Págs. 82-83. En Diego Gracia: Eundamentos de Bioética. Pág.25I

42. CIT. Rawls, John: “Las Libertades Fundamentales y su Prioridad". En John Rawls y Otros: Libertad. Igualdad y Derecho. Ariel-España 1988. la. 
Edicion. Tf́tulo original: Liberty, Equality and Law. Select Tanner lectures on Moral Philosophy. 1987. The Press Syndicate of the University of Cambridge.Pág 13 y ss.

43. VID. Diego Gracia: Eundamentos de Bioética. Pág.251 y 252.

44. VID. Diego Gracia: Eundamentos de Bioética. Pág.251 y 252.

45. Utilizamos un concepto de normas fundamentales en el sentido de referirnos a normas primarias, a normas que tienen o pueden tener con ciertas medidas y restricciones rango del más alto nivel, y que por tanto en sentido amplio pueden denotar un tópico constitucional. Además de advertir que las normas fundamentales utilizadas en este momento no es identificable con el concepto que podría retomarse de las normas de derecho fundamental. El concepto que se utiliza de norma fundamental es más amplio que norma de derecho fundamental.

46. CIT. Bartolomé, Clavero: "Garantie Des Droits". Emplazamiento Histórico del Enunciado Constifucional. En Revista de Estudios Políticos. Nueva época número 81, julio-septiembre 1993. Centro de Estudios Constitucionales. Madrid.Pág 7.

47. VID. El Preámbulo de la Constitución de El Salvador de 1983. No hay que olvidar tampoco que el Estado proclama la Libertad, y que este junto a la vida son también unos de los máximos bienes; el binomio Estado- Libertad sirven a su vez para auxiliar a la fundamentación de los principios y valores de la Constitución.

48. [] El agregado es nuestro.

49. CIT. M. García Canales: "Principios Generales y Principios Constitucionales". En Revista de Estudios Políticos. Nueva época número 64, abril-junio 1989. Centro de Estudios Constitucionales. Madrid.Pág.131.

50. En una similar perspectiva puede verse en Dworkin de como el derecho constitucional puede basarse en el error al actuar en formas pasivas en los aspectos historicistas. VID. DWORKIN, Ronald: El imperio de la justicia. De la teoría General del Derecho, de las decisiones e interpretaciones de los jueces y de la integridad política y legal como clave de la teoria y práctica.Traducción de Claudia Ferrari. Gedisa 1988.1a. Edición. Título original: Law's Empire. By Harvard University, Press, Cambridge, Mass 1986. Pág. 251 y ss.

51. De hecho y no por los canones establecidos en el derecho.

52. Abrir el abismo entre realidad y Constitución es quedarnos con una realidad sin norma o con norma sin realidad. VID. María del Pilar Hernández Martínez: "Reflexiones sobre la Tenría de la Constitución y del Derecho Constitucional. Bolelín Mexicano de Derecho Comparado, Nueva Serie, año XXV No 73. Enero- abril 1992. UNAM. Pág. 42 y ss.

53. CIT. José Ignacio Martínez García: "Ficciones en la Construcción del Derecho". En Revista Estudios Deusto. Universidad de Deusto. Bilbao. Vol 37/2,julio- diciembre de 1989.Pág 419. 
54. [] El agregado es nuestro.

55. CIT. Pablo Lucas Verdu: "Reflexiones en tomo y dentro del concepto de Constitución. La Constitución como norma y como integración polífica". En Revista de Estudios políticos. Nueva época número 83, enero-marzo 1994.Centro de Estudios Constitucionales. Madrid. Pág.25.

56. Acerca de atemporalidad en las constituciones VID. Maria del Pilar Hernández Martínez: Reflexiones sobre la teoría de la Constitución y del Derecho Constitucional. Pág. 41 y ss.

57. CIT. Jorge Uscatescu: "Evocación de Carl Schmitt". En Revista Folia Humanística. Tomo XXVIII, número 313, marzo-abril 1990. Barcelona.Pág. 158.

58. El presupuesto axiológico asume desde nuestra visión la conjunción de una axiología y la axiosofía en términos estrictos. Sabiendo que el terreno de la axiologla se delimita por "la estructura formal del reino de los valores, la delimitación de cada valor, la relación entre los diversos valores, así como las leyes formales que gobiernan a cada valor. La axiosofía en cambio, enfoca los contenidos de los valores. La axiología es referida a los valores, la axiosofía es estimativa". Cit. Werner Goldschmit: La Ciencia de la Justicia. (Dikelogía). Pág 18.

59. CIT. Rosiere Frondizi: Qué son los valores?. Brevarios del Fondo de Cultura Económica. México 1994. 12a. Reimpresión.Pág 151.

60. El interés general de hallarse subsumido por la noción del bien común y estrechamente correlacionado con la noción de función social.

61. VD. Demanda de inconstitucionalidad No.3-85. Sentencia 1989. En Gabriel Mauricio Gutiérrez Castro. Derecho Constitucional salvadoreño. Catálogo de Jurisprudencia (segunda edición). Número 7. Pág 170.

62. VID. Robert Alexy: Teoría de los Derechos Fundamentales. Traducción de Ernesto Garzón Valdés. Centro de Estudios Constitucionales. Madrid 1993. la. Edición. Pág 157 y ss. Título original: Theorie Der Grundrechte. Suhrkamp-Verlag. 1986.

63. Al respecto son significativas las aseveraciones del Profesor Manuel Alienza: "Es cierto que el jurista no carece en su travesía de puntos de referencia, pero tampoco cuenta con ninguna estrella polar que le indique inequívocamente el carnino a seguir; pues no todas las señales apuntan en la misma dirección o, si se quiere, las mismas señales son entendidas de maneras distintas, quizás también porque no todos los caminantes buscan llegar al mismo sitio". CIT. Manuel Atienza: Tras la Justicia. Una Introducción al Derecho y al razonamiento Jurídico. Ariel-Barcelona 1993. 1a. Edición. Pág. IX.

64. CIT. Rudolf Stammler: El Juez. El pensamiento filosófico Jurídico de Stammler. Editora Nacional. México 1980. la. Edición. Pág 61.

65. CIT. Gregorio Peces Barba Martínez: Etica Pública y Derecho. Discurso 
de recepción de Académico de número en la Real Academia de Ciencias Morales y políticas de Madrid.1993. Pág. 21.

66. VID. Manuel Atienza: Tras la Justicia Una Introducción al Derecho y al razonamiento Jurfdico. Pág. LX.

67. VID. H. Skolimowski: "Las cuatro tradiciones axiológicas del hombre occidental y hacia dónde vamos".Pág.272.

68. Acerca del concepto de valor. VID. Abelardo Torre: Los Valores Jurídicos en Introducción al Derecho. Perrot-Buenos Aires 1975. 7a Edición.

69. "Son los objetos hechos por el hombre actuando según valoraciones. Ejemplos un libro, una melodía, el derecho, la filosofía". CIT. Abelardo Torre: Los Valores Jurídicos en Introducción al Derecho. Pág 30.

70. VID. Salvador Verges Ramfrez: Derechos Humanos y Justicia. Evolución de la Justicia y el Progreso de los Derechos Humanos. En Revista Estudios Deusto. Universidad de Deusto. Bilbao. Segunda Epoca Vol. 39/2. JulioDiciembre 1991. Pág. 630.

71. CIT. Exposición de Motivos: Comisión de estudio del proyecto de Constitución. Informe único. Palacio Legislativo: San Salvador, 22 de julio de 1983. En anexo de Constitución. República de El Salvador 1983. Publicación del Ministerio de Justicia. San Salvador, marzo de 1992.Pág 184.

72. [] El agregado es nuestro.

73. CIT. Charles Handy: The Chinese Contract. Cap, 5. The age of Paradox, Harvard Business School Press, 1994. En boletín de apoyo, traducido al español para la Maestría en Administración y Dirección de Empresas. UCA. Curso 1995.

74. VID.El Método de Historización de los conceptos de Ignacio Ellacurfa. En Revista Estudios Centroamericanos ECA. Número 553-554 noviembre-diciembre 1994.

75. VID. Enrique Rickert: Ciencia Cultural y Ciencia Natural. Traducido del alemán por Manuel G. Morente. Colección Austral, Espasa Calpe- Argentina. 1945. 2a. Edición.Págs 64 y 65.

76. Véase por ello que en nuestro país hemos de adoptar posturas realistas, es decir que respondan a la realidad, que no se confundan con posturas que retomen apariencias de la realidad, ni tomen soluciones de carácter inmediatistas. Ser realista en esta perspectiva supone que aceptemos las dificultades de los problemas y la complejidad de los intereses que dificultan sus soluciones. Es partir del supuesto que las verdaderas soluciones se toman cuando se está atento a la realidad de la situación y de los intereses de los agentes sociales. Tomando además una postura de clarividencia, en el sentido de no ver imprudentemente, sino con prudencia aquello que está en el presente y más allá del presente inmediato. VID. Junta de Directores: Pronunciamiento en la Conmemoración del quinto aniversario de los mártires de la UCA, Universidad Centroamericana "José Simeón Cañas". El Salva- 
dor necesita realismo y esperanza. En Revista Estudios Centroamericanos ECA. Número 553-554 noviembre-diciembre 1994. Pág.1 180.

77. Lo cual puede hacer ver incluso a la Justicia como "evangelización".

78. Demanda de inconstitucionalidad No.3-85. Sentencia 1989. En Gabriel Mauricio Gutiérrez Castro. Derecho Constitucional salvadoreño. Pág 168. Sin embargo hay que admitir que también debe brindarse una protección a la minoría, especialmente si esta se vuelve débil, desarmada y desorganizada. En Goldschmit se retoma el punto: "la protección de la minoría debe realizarse contra la superioridad en el propio grupo (llamada protección de las minorías en sentido estricto). Pero también hay que amparar a los grupos más débiles contra grupos más poderosos". CIT. Werner Goldschmit: La Ciencia de la Justicia. (Dikelogía). Pág 221.

79. Esta preocupación puede verse más clara en cuanto políticas económicas, y en cuanto políticas sociales y culturales. Con esta interpretación hay que tener cuidado,- especialmente en la tarea de juzgamiento-ya que no solo por el hecho de estar en posición desventajosa, se le va dar preferencia inmediata. Hay que observar los casos, analizarlos e interpretarlos, en orden sistemático, no sólo con los principios, sino con los valores y derechos del ordenamiento.

80. VID. Junta de Directores: Pronunciamiento en la Conmemoración del quinto aniversario de los mórtires de la UCA, Universidad Centroamericana "José Simeón Cañas". El Salvador necesila realismo y esperanza.Pág 1180 y ss.

81. Esto es una interpretación relalivista propia del pensamiento de Prolágoras.

82. Sentencia de Amparo 65/90. Fundamento 6.

83. Sobre el sistema jurídico, o reductoramente natural y separada del ordenamiento jurídico.

84. La que identifica justicia con el derecho, justicia con la ley, justicia con la norma constitucional, o justicia legal.

85. Como resoluciones, interpretaciones y aplicaciones en el más alto nivel.

86. CIT. Eduardo García Maynez: Los valores jurídicos en Filosofía del Derecho. la. Edición 1974. Editorial Porrúa. Mexico Pág. 417.

87. La dificultad de tomar lo expreso y lo implícito nos remite a la aclaración de sus significados: entiéndase expreso lo que está en la Constilución. Esto probablemente porque se puede tratar de criticar este apartado al decir que la justicia no se mencionó en ninguno de los secciones que se especifican. Sin embargo es de observar que hay una conexión que se acerca más a lo expreso que a lo implícito de la justicia como rectora e informadora de esas normas que se plasmaron constitucionalmente. Por ejemplo, pudo haberse dicho que la justicia no es sistema democrático, por que la Constitución no lo dijo así (literalmente). Por eso tenemos que ejecutar la labor interpretativa, y he aquí el objeto del trabajo. Desentrañar lo que es y para que es la justicia en la Constitución. Creemos que desde nuestro punto de 
vista que lo expreso no es identificación con lo literal,es un poco más que este, lo cual nos lleva a ver zonas de "conexión directa" con la justicia . Asimismo lo implícito abarca zonas menos claras y en donde la labor interpretativa judicial tiene que decir y clarificar con un carácter más fuerte. Es ya más un asunto de punto de llegada de lo expreso, en donde hay que "refinar" el contenido de justicia. Por ejemplo las políticas del Ejecutivo que puedan tener un mayor malestar o bienestar para el individuo. Adviértese además que no es sólo lo que no está en la Constitución, sino lo que está pero que adquiere un sentido muy difuso en sentido duro.

88. Sentencia de amparo 20-1990, fundamento 3.

89. El tema se retoma en Zorilla cuando debate acerca de la función del valor superior de la justicia. Movilizando el informe de la justicia en las medidas del legislador constiluyente y, ordinario que colleven actuaciones sinceras, certeras inteleclualmente, aparte del adicional convencimiento moral y sin el afán publicitario, entre otras cosas. VID. Manuel Maria Zorilla Ruiz: Aplicación del Derecho Objetivo por la Justicia Constitucional y la Jurisdicción Ordinaria. En Revista de la Universidad de Deusto. Segunda época. Vol 42/1. Enero-Junio 1994. Págs. 173 y ss.

90. Por ejemplo recordemos a uno de los grandes representantes de la filosolía estoica: Séneca, para quien la estrechez del marco legal romano dejaba por fuera, la piedad y la humanidad (en De Ira 2,28), la clemencia (En De Los Beneficios 3,7) la Equidad y la Bondad (en De Clementia 2,7). VID. Olga Marlasca Martínez: Elementos Jurídicos y Extrajuridicos en el Derecho. En Revista Estudios Deusto. Universidad de Deusto. Segunda Epoca. Vol. 41/1 Enero-Junio 1993. Pág. 146.

91. VID. J.H. Von Kirchmann: La Jurisprudencia no es Ciencia. Madrid- Centro de Estudios Constitucionales 1983. 3a. Edición. Pág 11 y ss.

92. VID. Albert Calsamiglia: "Sobre la Ciencia Jurídica". Anuario de Derechos Humanos, número 4. Madrid-Facultad de Derecho de la Universidad Complutense. 1986-1987. Pág. 46.

93. VID. Norberto Bobbio: Contribución a la Teoría del Derecho. Editorial Debate-Madrid 1990. 1a. Edición. Pág 185.

94. CIT. José María Martínez Doral: "Sociólogos, Juristas, Filósofos. Apuntes para una metodología del derecho". En Revista Chilena de Derecho, volumen 17, número 3, septiembre-diciembre de 1990. facultad de Derecho Pontificia de la Universidad Católica de Chile. Págs 521 y ss.

95. Sentencia de Amparo 65-90, fundamento 6.

96. V D. RAWLS, John: “ Las Libertades Fundamentales y su Prioridad”.Pág 13 y ss.

97. No se confunda el término inmediato con directo; ante ello suponemos junto al profesor Asis que lo directo es la posibilidad de plantearse el valor justicia con independencia de cualquier precepto y lo inmediato como no necesidad de desarrollo o concreción. VID. Rafael de Asis Roig: Deberes 
$y$ obligaciones en la Constitución. Centro de Estudios Constitucionales-Madrid 1991. 1a. Edición. Pág 223.

98. CIT. Rudolf Stammler: El Juez. El pensamiento filos6fico Jurídico de Stammler. Pág 53.

99. La sala al respecto ha estimado que" en principio, los funcionarios públicos al interpretar las leyes y considerarlas inconstitucionales pueden no aplicarlas en el caso concreto, pero al existir una sentencia de la Corte Suprema de Justicia, actualmente por medio de la Sala de lo Constitucional, que declara que no existe inconstitucionalidad de una ley, decreto o reglamento, cesa la facultad de los funcionarios para declarar la inaplicabilidad de la disposición, pues es la Corte por medio de esta Sala a quien compete en definitiva, de un modo general y obligatorio, la interpretación de las normas constitucionales". VID. Sentencia de inconstitucionalidad. Ley Electoral 1985. En Gabriel Mauricio Gutiérrez Castro. Derecho Constitucional salvadoreño.Pág 151 y 152.

100. No caigamos tampoco en la identificación del derecho con justicia. Decimos que el principio clásico disociador queda atrás. Lo que refleja que ya no hay ése desligamiento característico. Asimismo no es de interpretar que al no haber disociación exista a su vez identificación. Esta no existe. El derecho no es justicia, ni la justicia es el derecho. Simplemente entre ambos se da una idea de «ligamento». En una relación que va de fundamentación, racionalización, ponderación y «aplicación inmediata».

101. CIT. Edgar Bodenheimer: Teoría del Derecho. Fondo de Cultura Económica. Traducido por Vicente Herrero. México 1994. 14a. Reimpresión. Tílulo original: Jurisprudence. 1940. Mc Graw-Hill Book Company Inc. New York. Pág.69.

102. Atienza, Manuel: Tras la justicia. Una Introducción al Derecho y al razonamiento Jurídico. Pág 93 y 94.

103. VID. Atienza, Manuel : Tras la justicia. Una Introducción al Derecho y al razonamiento Jurídico. Pág 207.

104. Admitiendo como obligaciones superiores "aquellas que acompañan a la propia concepción del sistema jurídico-político, constituyendo la expresión de sus postulados máximos, hasta el punto que el propio ordenamiento equipara su revisión a la de todo el texto constilucional". CIT. Rafael de Asis Roig: Deberes y obligaciones en la Constilución. Pág 207.

105. Una valoración crítica del pensamiento de Stammler puede encontrarse en L. Recasens Siches: Direcciones Contemporáneas del Pensamiento Jurídico. (La filosofía del Derecho en el siglo XX). Editora Nacional-México. Universidad de Santiago. 1a. edición. 1981. Pág 82 y ss.

106. Stare-Decisis, legalidad, estricto derecho, e irretroactividad, entre otros. VID. Gabriel Mauricio Gutiérrez Castro. Derecho Constilucional salvadoreño. Pág 211 y ss.

107. La sala de lo Constitucional ha sostenido en variadas ocasiones que el peti- 
cionario debe acreditar "ser titular de un derecho subjetivo" VID. Amparo N_1-E-86. Sentencia 1987; Amparo N_7-M -90. Improcedencia 1990. Amparo N_7-S-89. Sobreseimiento 1990. En Gabriel Mauricio Gutiérrez Castro. Derecho Conslitucional salvadoreño. Pág 252. y Pág 8.

108. Actualmente la Corte Suprema de Justicia tratando de proteger los derechos Constitucionales trabaja para incorporar como derechos constitucionales las normas que configuren el bloque de constitucionalidad. Doctrina que tiende a superar la concepción puramente formal o documental de la Constitución y que denota el conjunto normativo de jerarquía constitucional que se emplea para emitir un juicio sobre la constitucionalidad de las leyes y de otros actos sujetos al control judicial de la Corte Suprema de Justicia. VID. Arturo Hoyos: El Control Judicial y el Bloque de Constitucionalidad en Panamá. Boletín Mexicano de Derecho Comparado. XXV, número 75, septiembre-diciembre de 1992. Pág. 798.

109. CIT. Gregorio Peces Barba: Derecho y Derechos Fundamentales. Págs 323.

110. CIT. Alexy, Robert: Teona de los Derechos Fundamentales. Pág. 202. Alexy, da un salto cualitativo y cuantitativo en la concepción relacional de los derechos, al advertir en la relación ya no un carácter diádico (como podria advertirse en la teoria de los correlativos), sino un carácter tradico en la relación: en el orden de sujeto-destinatario-objeto. VID. Alexy, Robert: Teoría de los Derechos Fundamentales. Pág. 201 y ss.

111. CIT. En Gabriel Mauricio Gutiérrez Castro. Derecho Constitucional salvadoreño. Págs 9 y 37. 